\title{
Molecular imaging in the investigation of hypoglycaemic syndromes and their management
}

\author{
David A Pattison1,2,3 and Rodney J Hicks 1,4,5 \\ ${ }^{1}$ Centre for Cancer Imaging, Peter MacCallum Cancer Centre, Melbourne, Australia \\ 2Endocrinology Service, Peter MacCallum Cancer Centre, Melbourne, Australia \\ 3Department of Nuclear Medicine \& Specialised PET Services, Royal Brisbane \& Women's Hospital, Brisbane, Australia \\ ${ }^{4}$ Neuroendocrine Service, Peter MacCallum Cancer Centre, Melbourne, Australia \\ 5The Sir Peter MacCallum Department of Oncology, University of Melbourne, Melbourne, Australia
}

Correspondence should be addressed to D A Pattison Email

David.Pattison@health.qld. gov.au

\begin{abstract}
There has been recent progress in molecular imaging using a variety of cellular targets for the investigation of adult non-diabetic hypoglycaemic syndromes and its integration into patient management. These targets include peptide receptors (somatostatin receptors (SSTRs) and glucagon-like peptide-1 receptor (GLP-1R)) the amine precursor uptake and decarboxylation system utilising the diphydroxyphenylaline (DOPA) analogue 6-[ $\left.{ }^{18} \mathrm{~F}\right]-$-I-fluoro-I-3,4-dihydroxyphenylalanine (18F-FDOPA), and glycolytic metabolism with 2-[18F]fluoro-2-deoxy-D-glucose (FDG). Accurate preoperative localisation and staging is critical to enable directed surgical excision or enucleation with minimal morbidity and preservation of residual pancreatic function. Benign insulinoma has near ubiquitous dense GLP-1R expression enabling accurate localisation with radiolabelled-exendin- 4 compounds (e.g. ${ }^{68} \mathrm{Ga}-\mathrm{NOTA}$-exendin-4 PET/CT), whilst the rarer and more difficult to manage metastatic insulinoma typically express SSTR and is preferably imaged with radiolabelledSSTR analogues such as ${ }^{68} \mathrm{Ga}$-DOTA-octreotate (DOTATATE) PET/CT for staging and assessment of suitability for peptide receptor radionuclide therapy (PRRT). Similar to other metastatic neuroendocrine tumours, FDG PET/CT is used in the setting of highergrade metastatic insulinoma to provide important prognostic information that can guide treatment and determine suitability for PRRT. Interestingly, these three tracers appear to represent a spectrum of differentiation, which we conceptually describe as the 'tripleflop' phenomenon, with GLP-1R > SSTR > FDG in benign insulinoma and the opposite in higher-grade disease. This paper will review the clinical syndromes of adult hypoglycaemia (including a practical overview of the differential diagnoses to be considered), comparison of techniques for insulinoma localisation with emphasis on molecular imaging before discussing its implications for management of metastatic insulinoma.
\end{abstract}

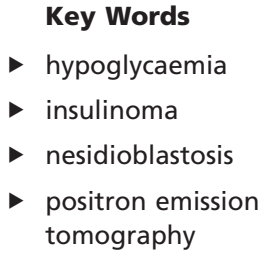

Endocrine-Related Cancer (2017) 24, R203-R221

\section{Introduction}

There have been significant developments in the investigation and management of adult non-diabetic hypoglycaemic syndromes over the last decade. Although selective arterial calcium stimulation testing (SACST) has been the gold standard investigation for many years, the rapid development and evaluation of molecular imaging 
techniques now provide the opportunity for noninvasive localisation and characterisation of insulinoma using a variety of cellular targets. These targets include peptide receptors, such as the somatostatin receptor (SSTR) and glucagon-like peptide-1 receptor (GLP-1R), the amine precursor uptake and decarboxylation (APUD) system utilising the diphydroxyphenylaline (DOPA) analogue 6-[18F]-L-fluoro-L-3,4-dihydroxyphenylalanine (18F-FDOPA), and glycolytic metabolism with 2-[18F] fluoro-2-deoxy-D-glucose (FDG). Accurate preoperative localisation and staging is critical to enable directed surgical excision or enucleation with minimal morbidity and preservation of residual pancreatic function. Furthermore, the insights learnt from the more prevalent benign insulinoma are critical to direct personalised therapy for rarer, but considerably more difficult to manage metastatic insulinoma. This paper will review the clinical syndromes of adult hypoglycaemia (including a practical overview of the differential diagnoses to be considered), comparison of techniques for insulinoma localisation with an emphasis on molecular imaging before a discussion of the implications for management of metastatic insulinoma.

\section{Clinical hypoglycaemia syndromes}

Although localisation of insulinoma is the primary role of molecular imaging in the investigation of adult hypoglycaemic disorders, it is important to recognise that the diagnosis of non-diabetic adult hypoglycaemia requires consideration of a broader range of differential diagnoses, which are listed in Table 1. The US Endocrine Society guideline for evaluation of adult hypoglycaemic disorders (Cryer et al. 2009) considers the 'seemingly well' individual presenting with hypoglycaemia to also be at risk of adult nesidioblastosis (including noninsulinoma pancreatogenous hypoglycaemia syndrome (NIPHS) and post-gastric bypass hypoglycaemia (PGBH)), insulin autoimmune hypoglycaemia and factitious hypoglycaemia (including accidental, surreptitious or malicious hypoglycaemia) due to administration of insulin or insulin secretagogues such as sulphonylurea. 'Ill or medicated individuals' may also develop nondiabetic hypoglycaemia due to various drugs, critical illnesses (including sepsis and hepato-renal failure), hormonal deficiencies (cortisol) or non-islet cell tumour hypoglycaemia (typically due to large mesenchymal tumoural secretion of insulin-like growth factor 2 (IGF-2) or its high-molecular-weight precursor (big IGF-2)).
Table 1 Differential diagnosis of hypoglycaemia in adults. Data from Cryer et al. (2009).

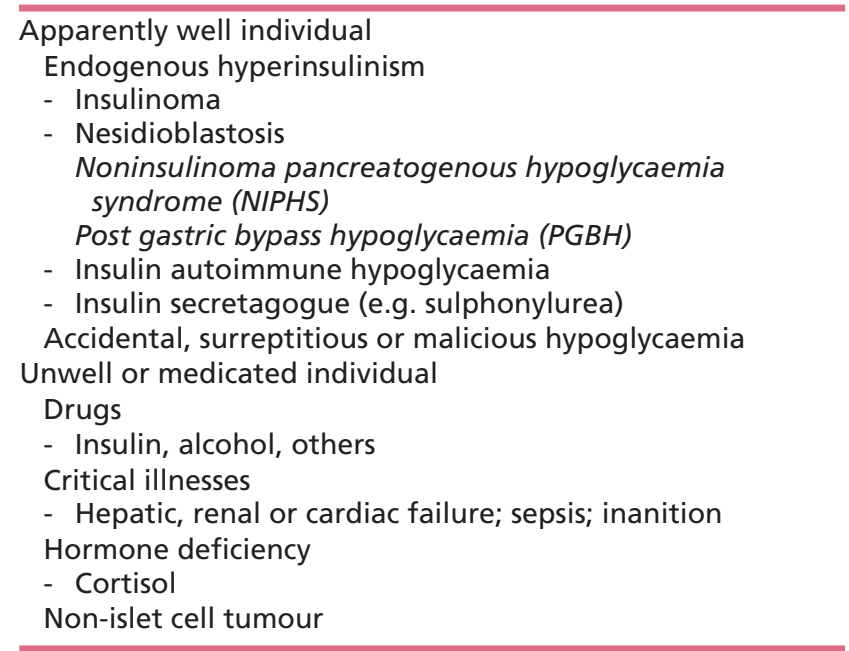

Many of these conditions are diagnosed biochemically in the appropriate clinical context (e.g. abnormal IGF2:IGF-1 ratio, cortisol deficiency or hyperinsulinaemic hypoglycaemia with undetectable C-peptide suggesting insulin administration) and will not be discussed in further detail in this review. The role of molecular imaging in adult hypoglycaemia is primarily focused upon localising the source of endogenous hyperinsulinaemic hypoglycaemia, usually due to either insulinoma or NIPHS, with different management implications. However, in the event of negative localisation studies (including advanced molecular imaging techniques) it is important to consider other differential diagnoses that may biochemically masquerade as endogenous hyperinsulinaemic hypoglycaemia (Paiva et al. 2006). Insulin autoimmune syndrome (IAS) (Uchigata \& Hirata 1999 ) is most commonly identified in Asian populations (particularly Japan) and is usually associated with post-prandial hypoglycaemia. It is characterised by markedly elevated insulin levels and may be associated with other autoimmune diseases. The diagnosis can be confirmed with assistance of laboratory testing to identify heterophilic interference and insulin and/or insulin-receptor antibodies. In these circumstances, one must also consider the possibility of mistaken (or surreptitious) administration of insulin secretagogues (e.g. sulphonylureas), recognising that many routine serum screening techniques for the first-generation sulphonylureas do not detect meglitinides or secondgeneration sulphonylureas, including glimepiride (Yates et al. 2009).
C 2017 Society for Endocrinology Printed in Great Britain
Published by Bioscientifica Ltd. 


\section{Insulinoma}

Insulinoma is a rare neuroendocrine tumour (NET) characterised by autonomous insulin secretion with an incidence of approximately 0.4/100,000 person years. It is more commonly seen in the fifth decade (median age 47 years, range 8-82 years) and there is a slight predominance $(\sim 60 \%)$ in females (Service et al. 1991). Approximately $90 \%$ are solitary, benign and $<2 \mathrm{~cm}$ in diameter (frequently $<1 \mathrm{~cm}$ ), and therefore present a challenge to localise (Klöppel et al. 2004). Approximately $5-10 \%$ are associated with multiple endocrine neoplasia type 1 (MEN1) syndrome and $<2 \%$ are extra-pancreatic in location (Oberg \& Eriksson 2005). They typically present with adrenergic (palpitations, diaphoresis, hunger, tremor, and anxiety) and neuroglycopaenic (confusion, visual disturbance, behavioural change, seizure, and coma) symptoms of hypoglycaemia in the fasting state. Post-prandial hypoglycaemia is more commonly associated with nesidioblastosis, but a very small proportion (6\%) of insulinomas may also present with symptoms solely occurring several hours after eating (Placzkowski et al. 2009). Diagnosis of insulinoma is confirmed by inappropriately elevated insulin, C-peptide and pro-insulin levels at the time of hypoglycaemia, with resolution of symptoms after glucose administration, satisfying the diagnostic criteria known as the Whipple triad (Whipple \& Frantz 1935, Cryer et al. 2009, Guettier et al. 2013). These blood samples may be taken opportunistically at the time of symptoms, or induced by prolonged supervised fasting or mixed-meal stimulation testing. The management of insulinoma is surgical excision and is often associated with long-term cure. Conventional imaging modalities have variable success in localisation of insulinoma, with reported accuracy from a contemporary study demonstrating sensitivity of abdominal CT (64\%) and magnetic resonance imaging (MRI) (75\%) (Druce et al. 2010). Endoscopic ultrasound (EUS) (65-94\%) and SACST (63-94\%) are highly operator dependent and the latter is particularly invasive and is only able to identify the pancreatic region of the tumour (McLean 2004, Guettier et al. 2009, Druce et al. 2010, Nockel et al. 2017). The opportunity for biopsy confirmation of insulinoma is an advantage of EUS. However, its scope is limited to evaluation of the primary tumour within the pancreas and is generally unable to assess for distant metastatic disease, which establishes the diagnosis of malignant insulinoma.

\section{Non-insulinoma pancreatogenous hypoglycaemia syndrome (NIPHS)}

NIPHS is characterised by episodes of neuroglycopaenia due to endogenous hyperinsulinaemic hypoglycaemia typically, but not always, occurring after a meal. Conventional radiological localisation procedures are always negative in this setting. The diagnosis is usually made on the basis of clinical presentation, endogenous hyperinsulinaemic hypoglycaemia and positive SACST, although ultimately pathological confirmation is necessary for definitive diagnosis given substantial overlap in presentation with insulinoma. SACST with hepatic venous sampling is an interventional radiological technique to localise or regionalise the occult insulinoma, or regionalise the most hyperfunctioning pancreatic tissue. A recent analysis (Thompson et al. 2015) of 116 patients with biochemical evidence of hyperinsulinaemic hypoglycaemia and inconclusive imaging compared the results of SACST with histopathology (42 insulinoma, 74 nesidioblastosis). They found the maximum hepatic venous insulin concentration and the relative-fold increase in hepatic venous insulin concentration after calcium stimulation were significantly higher in the insulinoma group. This is important preoperative information, as nesidioblastosis is preferably managed conservatively with or without pharmacologic therapy.

\section{Post-gastric bypass hypoglycaemia (PGBH)}

PGBH occurs exclusively post-prandially, is also characterised by endogenous hyperinsulinaemic hypoglycaemia and typically begins 6 months or later following surgery. The mechanisms underlying $\mathrm{PGBH}$ are incompletely understood but are likely multifactorial and potentially include inappropriate secretion of insulin and incretin hormones such as GLP-1, increased glucose effectiveness and insulin response to oral stimuli, dysfunction of counter-regulatory hormones such as glucagon, reduced rate of insulin clearance and rapid improvement in insulin sensitivity following weight loss (Patti et al. 2005, 2015, Goldfine et al. 2007, Salehi et al. 2014). Epidemiologically, the 5-year incidence of PGBH among non-diabetic individuals is $13.3 \%$ and the risk is increased with lower preoperative body mass index, lower preoperative $\mathrm{HbA1c}$, and higher 6-month percent of excess body weight loss (Lee et al. 2016). In most cases, PGBH is effectively managed with carbohydrate restricted diet, consisting of 6 meals per day with up to maximum 
of $30 \mathrm{~g}$ carbohydrate each (Van Meijeren et al. 2017). Additional medication is needed in approximately onethird of patients, which can include the alpha-glucosidase inhibitor acarbose to slow the carbohydrate absorption and thus reduce post-prandial insulin secretion, and diazoxide to reduce insulin secretion. Surgical procedures such as partial pancreatectomy or reversal of gastric bypass are not always successful (Patti et al. 2005). However, the co-existence of insulinoma in the setting of NIPHS (Bright et al. 2008, Sowa-Staszczak et al. 2013) and PGBH (Zagury et al. 2004, Service et al. 2005) has been reported in rare cases and must be considered particularly in the setting of late, severe or persistent hypoglycaemia following bariatric surgery. The diagnosis is challenging due to an overlap in clinical presentation and biochemical evidence of endogenous hyperinsulinaemia. A confident diagnosis is critical before subjecting a patient to further high-risk surgery, however localisation by conventional radiological techniques is limited, EUS is not practical in patients with a small, remnant gastric pouch and results of SACST are likely to be affected by prior surgery.

\section{Pathophysiology of hypoglycaemia syndromes}

Approximately $5-10 \%$ of insulinoma cases are associated with MEN1. MEN1 encodes a nuclear protein menin, a tumour suppressor that acts as an adapter and interacts with partner proteins involved in crucial activities including transcriptional regulation, cell division, proliferation, and genome stability. Adult NIPHS may be sporadic, occur in the post-gastric bypass setting (Service et al. 2005) or be associated with underlying germline mutation (e.g. activating mutation of glucokinase gene (Ajala et al. 2016)) indicating overlap in selected cases with congenital hyperinsulinism. Histopathologically, insulinoma is characterised by an abundance of insulin secreting cells with large nucleoli and very little pleomorphism arranged in a trabecular pattern or as sheets of uniform spindle-shaped cells, well-circumscribed with fibrous septa separating it from normal tissue with an absence of exocrine pancreatic components. In contrast, focal congenital hyperinsulinism demonstrates nodular hyperplasia of islet-like cell clusters, with hypertrophied islet cells and large pleomorphic nucleoli without a clear margin of demarcation from adjacent acinar components (Sempoux et al. 2003). Diffuse nesidioblastosis is characterised by islet cell hyperplasia, with enlarged and/ or more numerous islets, some of them adjacent to and budding from ducts (ductuloinsular complexes) indicating active formation of endocrine cells by multipotent cells in basal layer of the ducts (Solcia et al. 1997). Interestingly, pathological features of nesidioblastosis such as increased islet number have not been consistently observed in the few pathological specimens of PGBH available for examination (Meier et al. 2006). This suggests that the hypoglycaemia observed in this setting may be due to the dysregulation of islet cell function rather than solely an increase in the mass (Patti \& Goldfine 2014).

These pathological differences have implications on the ability of molecular imaging to characterise these diseases. It may be argued that the foundation for the current approach to molecular imaging of insulinoma was established by Reubi et al. using in vitro autoradiography to assess the incidence and density of expression of various peptide receptors on tissue samples from a series of 27 insulinomas (Reubi et al. 2003). Thirteen peptide receptors were tested, including two vasoactive intestinal peptide (VIP) receptors, SSTR subtypes 1-5, three bombesin receptor subtypes, cholecystokinin (CCK) subtype 1 and 2, and GLP-1R. SSTR2 was expressed in insulinoma less frequently in 18/26 (69\%) and intensely (mean density $3807 \mathrm{dpm} / \mathrm{mg}$ tissue) than in other gasteroenteropancreatic (GEP) NETs in the study. Conversely, nearly all cases demonstrated very intense GLP-1R expression at a mean density of $8133 \mathrm{dpm} / \mathrm{mg}$ tissue in 25/27 (93\%) insulinomas. Notably, the $2 / 27$ cases in this series lacking GLP-1R expression demonstrated intense staining (up to $6477 \mathrm{dpm} / \mathrm{mg}$ tissue) for SSTR2, suggesting a 'flip-flop' phenomenon. In contrast, the same group (Reubi et al. 2010) demonstrated normal GLP-1R expression in seven samples of pancreatic tissue from patients with PGBH (mean density $1483 \mathrm{dpm} /$ mg tissue) compared to 10 normal controls (1563 dpm/ $\mathrm{mg}$ tissue), and much less than that seen in six cases of benign insulinoma (mean density $8302 \mathrm{dpm} / \mathrm{mg}$ tissue). This provided the rationale for GLP-1R imaging in the localisation of insulinoma but indicates that it is less likely to be useful in the evaluation of PGBH.

\section{Molecular imaging modalities}

The major molecular imaging targets for localisation of hypoglycaemic syndromes are demonstrated on Fig. 1 including somatostatin receptors (usually ${ }^{111} \mathrm{In}-$ or ${ }^{68} \mathrm{Ga}$-labelled somatostatin agonists), large amino acid transporter type 2 (18F-DOPA) and the GLP-1R ${ }^{68} \mathrm{Ga}$-exendin-4). In the less common population of 


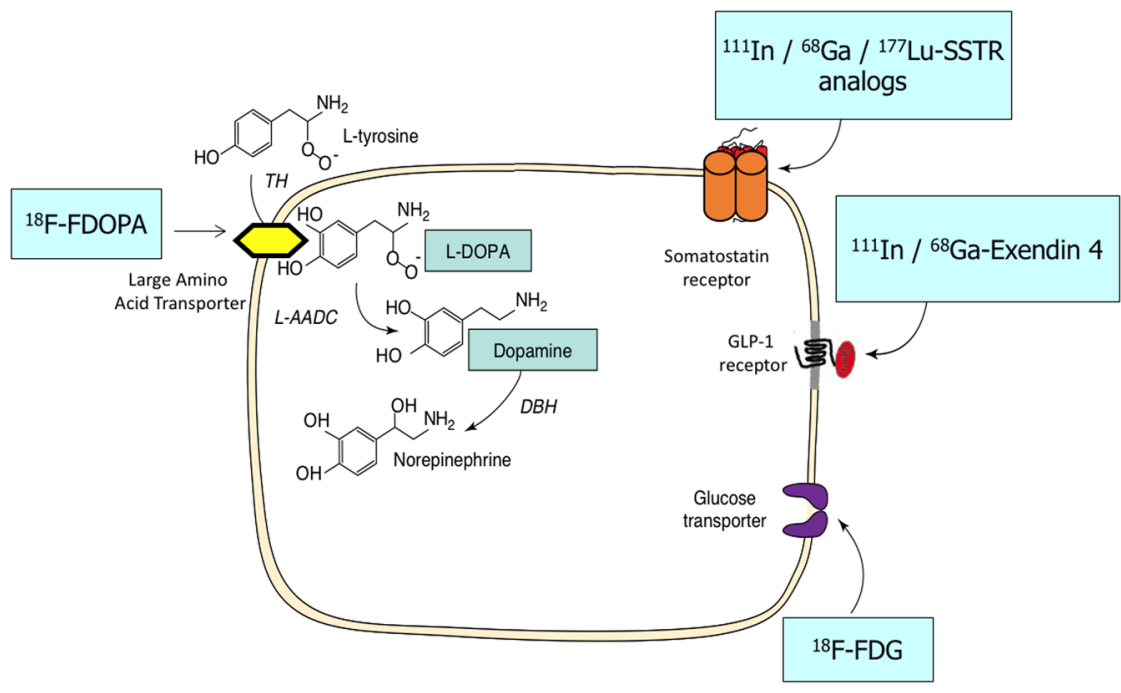

\section{Figure 1}

Molecular targets currently utilised for imaging and radionuclide therapy of insulinoma. Adapted from Trends in Endocrinology \& Metabolism, Vol 16 issue 2, Ilias I, Shulkin B \& Pacak K, New functional imaging modalities for chromaffin tumors, neuroblastomas and ganglioneuromas, Pages 66-72, Copyright (2005), adapted with permission from Elsevier. malignant insulinoma, uptake of FDG via membrane glucose transporters is utilised to assess prognosis and exclude SSTR -ve/FDG +ve sites of metastatic disease in patients deemed otherwise suitable for peptide receptor radionuclide therapy (PRRT).

An understanding of the evolution in molecular imaging technology over the last three decades, in addition to details of the new imaging tracers, has important implications for interpretation of the apparently conflicting hypoglycaemia molecular imaging literature. Planar scintigraphy, providing basic low resolution twodimensional images of whole tracer distribution, has changed little since the invention of the Anger gamma camera in the 1960s. Single photon emission computed tomography (SPECT) imaging, often overlaid with low dose computed tomography (CT) images for anatomic localisation, has been developed over the last two decades and is now near universally available. However, there is substantial difference in the imaging quality and resolution of these modalities, which must be considered when comparing studies utilising 111In-octreotide scintigraphy over this timeframe. Development of positron emission tomography (PET) has enabled dramatic improvement in spatial resolution with reduced radiation exposure, and greater patient convenience with shorter imaging times (Hofman et al. 2012). A recent case report neatly demonstrates this principle, whereby a patient with a $2.1 \mathrm{~cm}$ insulinoma was not identified on endoscopic US or ${ }^{111}$ In-pentetreotide scan but clearly localised on ${ }^{68} \mathrm{Ga}$-DOTA-octreotate ( ${ }^{68} \mathrm{Ga}$-DOTATATE) PET/ CT (Sadowski et al. 2014). Thus, it is critically important to consider the type of imaging technology used when comparing the reported accuracy of studies because the spatial resolution of 'somatostatin receptor imaging' or 'radiolabelled octreotide scanning' (Druce et al. 2010) may vary between several centimetres for ${ }^{111}$ In-octreotide planar scintigraphy, $1-2 \mathrm{~cm}$ for ${ }^{111}$ In-octreotide SPECT/CT to $<5 \mathrm{~mm}$ for ${ }^{68} \mathrm{Ga}$-DOTATATE PET/CT.

Molecular imaging provides confident localisation due to in vivo disease characterisation such as focal intense SSTR2 or GLP-1R expression, which is required to proceed with invasive and potentially morbid
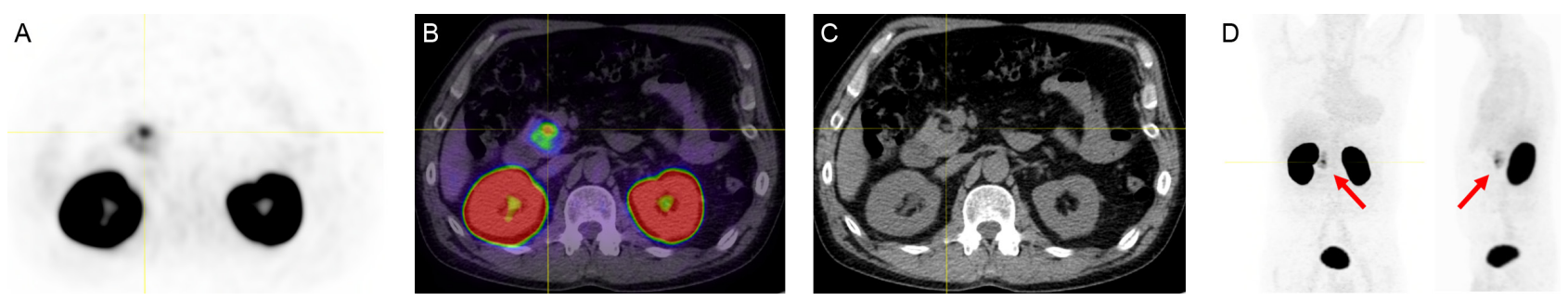

Figure 2

A 60-year-old man with 25-year history of endogenous hyperinsulinaemic hypoglycaemia referred for ${ }^{68}$ Ga-DOTA-exendin-4 PET/CT with prior unsuccessful partial pancreatectomy/splenectomy for localisation of presumed insulinoma. Axial PET (A) and fused axial PET/CT images (B) demonstrate focal intense uptake associated with a sub-cm nodule in the residual neck of pancreas with surrounding fat density evident on co-registered low dose CT (C). Red arrows on PET maximum intensity projections ( $D$, left coronal \& right sagittal) corresponds to focal lesion.

http://erc.endocrinology-journals.org DOI: $10.1530 /$ ERC-17-0005
() 2017 Society for Endocrinology Printed in Great Britain
Published by Bioscientifica Ltd 
pancreatic surgery such as Whipple's procedure. Figure 2 demonstrates the confident localisation using ${ }^{68} \mathrm{Ga}$-DOTAexendin- 4 of a suspected insulinoma in the remnant neck of pancreas in a patient with a 25-year history of endogenous hyperinsulinaemic hypoglycaemia treated with prior partial pancreatectomy/splenectomy. The site of disease remained occult despite multiple CT studies, SACST, MRI, EUS and ${ }^{68} \mathrm{Ga}$-DOTATATE PET/CT and had been maintained on high dose diazoxide and diuretic therapy. Given the potential morbidity associated with further surgery in this extreme case example, confident localisation was necessary before planning any further intervention.

\section{Somatostatin receptor imaging}

There are five known somatostatin receptor subtypes, which are commonly expressed to a varying degree on neuroendocrine tumour cells. The radiolabelled somatostatin analogue 111In-DTPA-octreotide was developed at the Erasmus Medical Centre in the Netherlands for imaging NETs in 1989 (Lamberts et al. 1990). More recently, radiolabelling of octreotide with the gamma emitter ${ }^{111}$ In has been largely superseded by the positron emitter ${ }^{68} \mathrm{Ga}$ labelled to octreotate, which provides the advantages of the greater spatial resolution of PET technology, lower radiation dose, greater patient convenience, and overall lower cost. Three compounds are now in use including $\left[{ }^{68} \mathrm{Ga}-\mathrm{DOTA}{ }_{0}-\mathrm{Ty}_{3}\right]$ octreotate (DOTATATE), $\quad{ }^{68} \mathrm{Ga}^{\mathrm{BOOTA}} \mathrm{D}_{0}-\mathrm{Ty}_{3}$ ] octreotide (DOTA-TOC), and $\left[{ }^{68} \mathrm{Ga}-\mathrm{DOTA} 0_{0}-\mathrm{NaI}_{3}\right]$ octreotide (DOTA-NOC). These have varying SSTR subtype specificity with highest affinity for SSTR2, SSTR5, and SSTR3/5, respectively. ${ }^{68} \mathrm{Ga}$-DOTATATE is the preferred tracer in our institution given SSTR2 is the predominant subtype overexpressed in insulinoma (and other GEP-NETS). Indications for somatostatin imaging in hypoglycaemic syndromes include localisation and staging of insulinoma in addition to its role as a theranostic investigation to determine suitability for PRRT of metastatic insulinoma. DOTATATE (NETSPOT) has recently been approved by the FDA for use in the USA, whereas DOTA-TOC has been approved by the EMA for use in Europe.

111In-DTPA-octreotide The reported sensitivity of ${ }^{111}$ In-octreotide scintigraphy for insulinoma localisation is variably between 20 and $60 \%$ in several series (Krenning et al. 1993, De Herder et al. 2005, Vezzosi et al. 2005). The low sensitivity demonstrated for octreotide scintigraphy in the study by Vezossi et al. (4/17 cases positive, 24\%) may reflect the poor imaging resolution of this technique. However, the limited expression of SSTR2a receptors in $7 / 17$ cases $(41 \%)$ of this series suggests a physical threshold for the utility of SSTR-based insulinoma imaging. However, SPECT imaging performed at $4 \mathrm{~h}$ has been shown to incrementally improve the localisation of insulinoma compared with planar scintigraphy at 4 and $24 \mathrm{~h}$ (Schillaci et al. 2000).

68Ga-DOTATATE PET/CT No prospective study has been performed specifically to evaluate ${ }^{68} \mathrm{Ga}$-DOTATATE PET/CT for the localisation of insulinoma. However, a recent retrospective review of pathologically confirmed insulinoma demonstrated successful localisation in 9/10 cases using this modality (Nockel et al. 2017). Another retrospective review of 13 patients with histopathological correlation of hyperinsulinaemic hypoglycaemia (eight benign insulinoma, two malignant insulinoma and three nesidioblastosis) demonstrated positive SSTR PET/ CT ( ${ }^{68} \mathrm{Ga}$-DOTATATE or ${ }^{68} \mathrm{Ga}$-DOTA-TOC) in $11 / 13$ patients (Prasad et al. 2016, 8). In this series, 8/10 (80\%) specimens stained strongly to moderately positive for SSTR2 immunohistochemistry. Figure 3 is a case example of confident localisation of multifocal residual disease
A

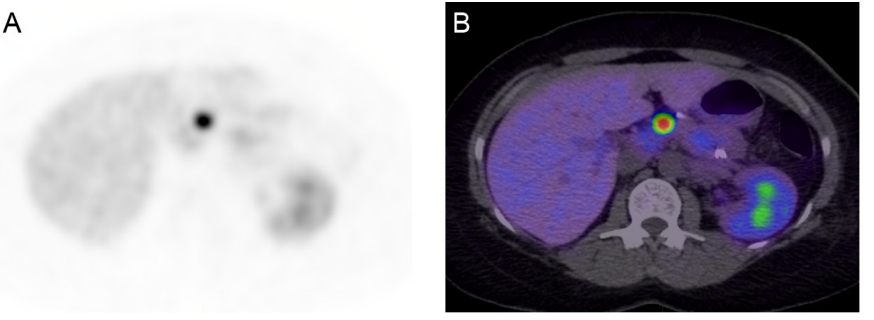

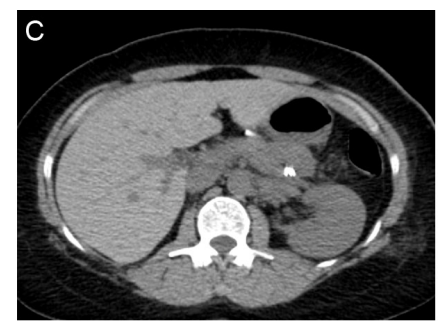

$\mathrm{D}$

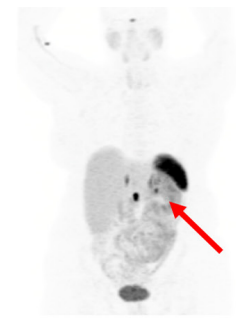

Figure 3

A 48-year-old woman with persistent hypoglycaemia referred for ${ }^{68} \mathrm{Ga}$-DOTA-octreotate PET/CT for the assessment of residual disease or distant metastases following enucleation of a presumed solitary insulinoma. Axial PET (A) and fused axial PET/CT images (B) demonstrate focal very intense uptake (SUVmax 40) in the body of pancreas without evident abnormality on co-registered low dose CT (C) at this site. Red arrow on PET maximum intensity projection (D) identifies additional focus of intense uptake (SUVmax 22) corresponding to a lesion in the pancreatic tail. 
within the body and tail of pancreas in the setting of persistent hypoglycaemia following enucleation of an apparently solitary insulinoma. As discussed later (see 'Future hypoglycaemia imaging research' section), both these studies are potentially subject to verification bias. It would be important to also understand the total number of cases investigated for hyperinsulinaemic hypoglycaemia with ${ }^{68} \mathrm{Ga}$-DOTATATE in confirming these apparently high sensitivity results. ${ }^{68} \mathrm{Ga}$-DOTATATE also appears accurate in patients with MEN1, prospectively demonstrating very high uptake (median SUVmax 72.8), significantly greater sensitivity and management impact than either CT or ${ }^{111}$ In-pentetreotide SPECT/CT in a cohort of 26 patients with MEN1, including three with insulinomas (Sadowski et al. 2015).

The majority of metastatic insulinoma cases included in reported series demonstrate significant avidity on somatostatin receptor imaging (Schillaci et al. 2000, van Schaik et al. 2011, Costa et al. 2013, Prasad et al. 2016). In contrast with the results from studies of benign insulinomas, a molecular imaging study of 11 patients with metastatic insulinoma targeted SSTR2 ${ }^{68} \mathrm{Ga}$ DOTATATE PET/CT) and GLP-1 receptors (111In-exendin-4 SPECT/CT) demonstrated relatively low GLP-1R targeting in only 4/11 metastatic cases, and higher than expected SSTR2 targeting in 8/11 cases (Wild et al. 2011). The two receptor types were both positive in only one case of metastatic insulinoma suggesting a 'flip-flop' relationship between expression of these two receptor types. This supports our experience with metastatic insulinoma with the vast majority of cases having high uptake on ${ }^{68} \mathrm{Ga}$ DOTATATE PET/CT. Further evidence of an association between SSTR expression and malignancy in insulinomas was identified in a quantitative PCR analysis of SSTR5 expression in a series of 16 primary insulinomas (four of which were plurihormonal) and two insulinoma metastases (de Sa et al. 2006). Interestingly, SSTR5 mRNA was positively correlated with histological features of tumour aggressiveness, including large tumour diameter, proportion of cells with nuclear atypia, and plurihormonal secretion. Recently, plurihormonal secretion (particularly with secondary insulin secretion) has been associated with increased mortality in a large cohort of metastatic pancreatic NETs (Crona et al. 2016). Given the inhibitory effects of activated SSTR5 on the cell cycle, it is postulated that increased SSTR5 expression in more biologically aggressive tumours may represent an adaptive compensatory cellular response to increased proliferation. A 'flip-flop' phenomenon is well recognised in metastatic NET representing a spectrum between well-differentiated predominantly SSTR avid lesions to poorly differentiated predominantly FDG avid disease (Hofman \& Hicks 2012). This additional inverse relationship between GLP-1R and SSTR expression leads to what may be described as a 'triple-flop' phenomenon in insulinoma, with increasing malignancy during progression from GLP-1R avid (benign) vs SSTR avid (malignant well-differentiated) vs FDG avid (malignant poorly differentiated). This apparent spectrum of molecular imaging phenotype is evident in a case of metastatic insulinoma described in Fig. 4. Furthermore, a theoretical explanation for the relatively low GLP-1R expression in bulky metastatic insulinoma vs intense expression in small benign insulinoma may reflect the pathophysiological role of the GLP-1R in hypoglycaemia due to insulinoma, such that tumours with greater GLP-1R density are more likely to manifest severe symptoms of hypoglycaemia at a much smaller size, when lesions are more likely to be benign.

\section{F-FDOPA}

${ }^{18} \mathrm{~F}-\mathrm{FDOPA}$ is taken up by neuroendocrine and islet cells via the large amino acid transporter (LAT1/4F2hc) and, like DOPA, it is subsequently decarboxylated by cytosolic L-aromatic amino acid decarboxylase and stored in vesicles (Santhanam \& Taieb 2014). The LAT1/4F2hc transporter is coupled with the mammalian target of rapamycin (mTOR) signalling pathway, which plays a critical role in cell growth and cell cycle progression. Notably, there is typically slightly higher uptake in the pancreatic head relative to the rest of the pancreas, potentially limiting the detection of lesions in this region. In addition, there can be prominent activity in the gallbladder and biliary tract. ${ }^{18} \mathrm{~F}-\mathrm{FDOPA}$ is excreted via the kidneys and there is also low-grade uptake in the heart, liver, and basal ganglia (Meintjes et al. 2013).

${ }^{18} \mathrm{~F}-\mathrm{FDOPA}$ has an established role for the differentiation between focal and diffuse forms of congenital hyperinsulinism (Otonkoski et al. 2006, Barthlen et al. 2008), but its role in the investigation of adult hypoglycaemia is more controversial. An original series reportedly correctly localised pancreatic lesions in 9/10 cases, including one case with hepatic metastases and two cases of B-cell hyperplasia (Kauhanen et al. 2007). However, these favourable results were not reproduced in a subsequent study (Tessonnier et al. 2010), which identified only $1 / 6$ histopathologically proven lesions due to diffuse background physiologic pancreatic activity. Notably, the single true-positive localised insulinoma was in an 8-year-old boy with MEN1. More recently,

Published by Bioscientifica Ltd 

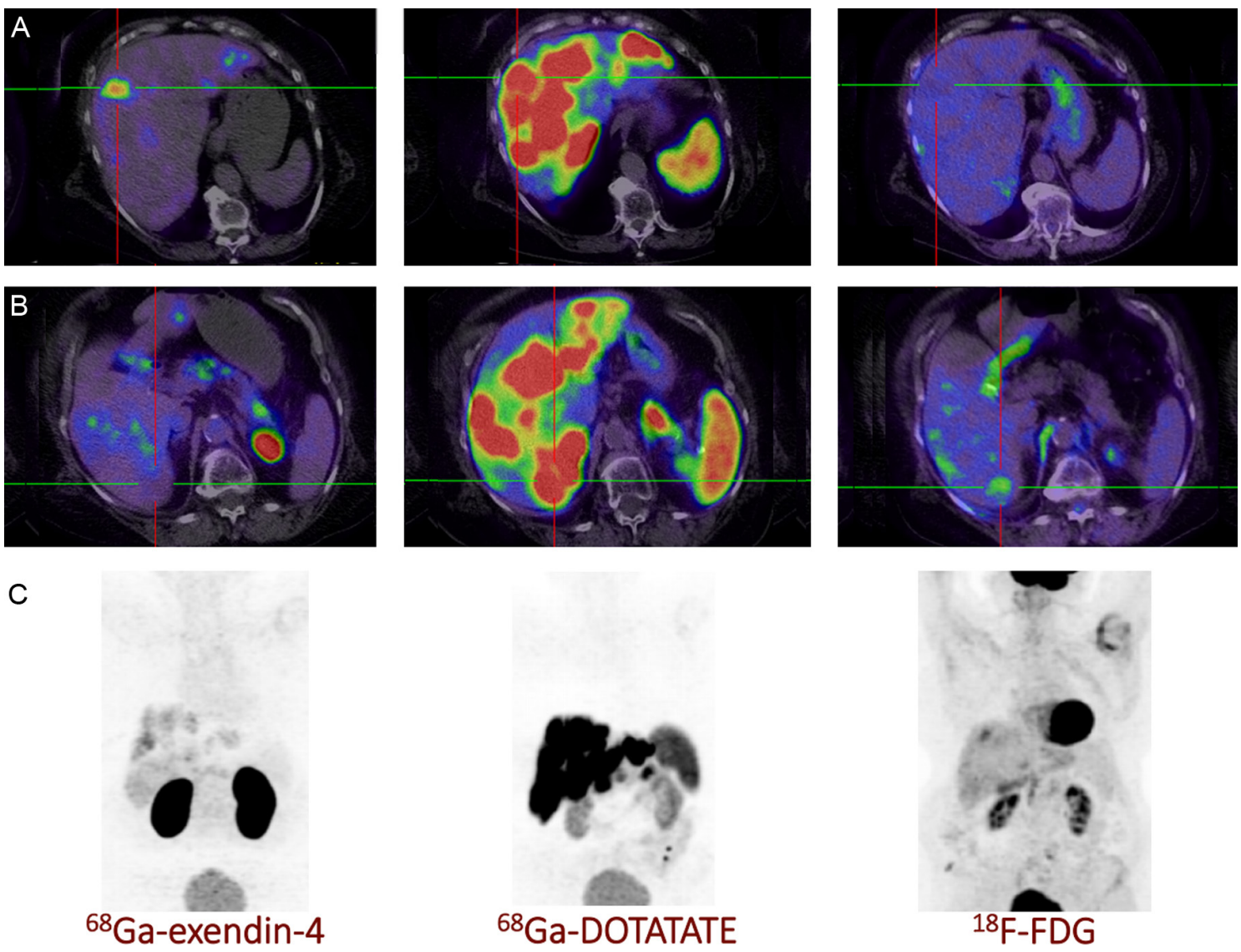

Figure 4

A 71-year-old woman with refractory hypoglycaemia secondary to metastatic insulinoma was referred for ${ }^{68} \mathrm{Ga}$-DOTA-exendin-4 (left column), ${ }^{68} \mathrm{Ga}$-DOTATATE (middle column) and FDG (right column) PET/CT for assessment of suitability for peptide receptor radionuclide therapy (PRRT). Row A demonstrates site of presumed well-differentiated disease (crosshairs) with focal intense GLP-1 receptor expression without any FDG avidity, whilst row (B) corresponds to a site with presumably higher grade disease with no GLP1 receptor expression but mild FDG avidity. Note that all sites of metastatic disease demonstrate very intense ${ }^{68} \mathrm{Ga}$-DOTATATE uptake (Krenning score 4; i.e. uptake > spleen) indicating suitability for treatment with PRRT.

the same group have published their findings using carbidopa premedication to inhibit peripheral aromatic amino acid decarboxylase (AADC) in background physiologic pancreatic tissue, with successful localisation in $8 / 11$ cases of histopathological proven cases (73\%), including one metastatic case (Imperiale et al. 2015). Consequently, although carbidopa premedication is not required in infants with congenital hyperinsulinism due to low expression of AADC in immature acinar cells, this study suggests that it is necessary in adults undergoing investigation of hyperinsulinaemic hypoglycaemia with ${ }^{18}$ F-FDOPA to optimise the pancreatic tumour:background ratio.

\section{Glucagon-like peptide-1 receptor (GLP-1R) imaging}

GLP-1 plays a diverse role in glucose homeostasis including the incretin effect, whereby an oral glucose load produces a greater insulin response than that of an isoglycaemic intravenous glucose solution. GLP-1Rs are widespread within the gastrointestinal tract, including the exocrine and endocrine pancreas, and are overexpressed in various NETs, particularly benign insulinomas (Korner et al. 2007). The biological role of GLP-1 on tumour cells remains uncertain, although it has been shown to stimulate proliferation and inhibit apoptosis of insulinoma cells in vitro. Exendin-4, originally isolated from the saliva of the Gila monster, is a long-acting GLP-1 analogue used for treatment of type 2 diabetes. This precursor has been successfully radiolabelled with 111In as [Lys40(Ahx [6-aminohexanoic acid]-DOTA-111In) NH2]-exendin-4 (111In-DOTA-exendin-4) and 99mTc- as [Lys40(Ahx-HYNIC-99mTc/EDDA)NH2]-exendin-4 (99mTcHYNIC-exendin-4) for imaging on a SPECT/CT gamma camera (Wild et al. 2010). ${ }^{99 \mathrm{~m} T c}$ is cheaper, more widely available, and provides lower radiation dose but ${ }^{111} \mathrm{In}$ 
provides the opportunity for delayed imaging out to 3 days to enable renal clearance of radiotracer. The two most extensively investigated ${ }^{68} \mathrm{Ga}$-exendin-4 PET tracers are [Lys40(Ahx-DOTA- ${ }^{68} \mathrm{Ga}$ )NH2]-exendin-4 ( ${ }^{68} \mathrm{Ga}$-DOTAexendin-4) (Wild et al. 2010) and ${ }^{68} \mathrm{Ga}-\mathrm{NOTA}-\mathrm{MAL}-\mathrm{cys} 40-$ exendin-4 ( ${ }^{68} \mathrm{Ga}$-NOTA-exendin-4) (Luo et al. 2015). Both compounds demonstrate very intense uptake within the kidneys due to urinary excretion, with very low-grade physiologic uptake in other organs including the pancreas and duodenum. The widespread availability, low cost, and short physical half-life have driven the popularity of these ${ }^{68} \mathrm{Ga}$-labelled tracers. A metastatic insulinoma case imaged with $\left[{ }^{68} \mathrm{Ga}\right] \mathrm{Ga}$-DO3A-VS-Cys40-Exendin-4 has also been reported (Eriksson 2014), but high uptake in background pancreas was noted. In a comparative study, ${ }^{68} \mathrm{Ga}$-labelled exendin- 4 compounds ligands were shown to have approximately 10 -fold lower mean effective dose than the same ligand labelled with ${ }^{64} \mathrm{Cu}$ (Mikkola et al. 2014) and the majority of ${ }^{18} \mathrm{~F}$-labelled compounds have demonstrated relatively high background activity in the liver and intestines (Kiesewetter et al. 2012).

It is important to note that transient exacerbation of hypoglycaemia is a common occurrence after radiolabelled-exendin-4 imaging. The median reduction in the blood glucose level was $1.3 \mathrm{mmol} / \mathrm{L}$ (range 0.8 $2.1 \mathrm{mmol} / \mathrm{L}$ ) with a nadir occurring approximately $40 \mathrm{~min}$ after injection in a large series of patients imaged for insulinoma localisation with ${ }^{111}$ In-exendin-4 (Christ et al. 2013). Twenty of 30 patients in this study required exogenous glucose infusion for hypoglycaemia, whereas more recent studies (Antwi et al. 2015, Luo et al. 2016) routinely co-administer glucose infusion in all patients to minimise the risk of hypoglycaemia. It has been observed that hypoglycaemia does not occur in patients undergoing radiolabelled-exendin-4 imaging for other indications (e.g. medullary thyroid carcinoma) (SowaStaszczak et al. 2016), or in healthy volunteers treated with the GLP-1 analogue therapy (Lerche et al. 2009), but that hypoglycaemia has occurred in a patient receiving the GLP-1 analogue therapy for diabetes with occult insulinoma (Ruby et al. 2014), and, in our experience, regularly occurs during radiolabelled-exendin-4 imaging for insulinoma. This phenomenon suggests that use of GLP-1 stimulation as a diagnostic test for insulinoma warrants prospective evaluation.

Following early favourable results in small series using ${ }^{111}$ In-DTPA-exendin-4 (Wild et al. 2008, Christ et al. 2009), it was used in a prospective multicentre imaging study performed at centres in Germany, Switzerland, and UK evaluating the accuracy of ${ }^{111}$ In-DTPA-exendin-4 with SPECT/CT imaging for localisation of insulinoma (Christ et al. 2013, 111). Of 23 assessable patientsIn DTPAexendin-4 SPECT/CT had a higher sensitivity (95\%) than CT/MRI (47\%). Insulinomas in seven patients were only localised using 111In-DTPA-exendin-4, with resultant high management impact. However, there were four false positive results (two adult nesidioblastosis and two uncharacterised lesions) resulting in a positive predictive value of $83 \%$. The single confirmed false negative case was a metastatic insulinoma, again the concept of a loss of this receptor in parallel with malignant transformation. For 20 of 25 patients, images demonstrated intense focal uptake at $4 \mathrm{~h}$ after injection. In the remaining five patients, only late scans at or after 3 days showed conclusive results after clearance of background renal activity. SACST correctly localised the vascular territory in 5/7 (71\%) patients. Of 11 patients imaged with EUS, 7/8 insulinomas were localised (sensitivity $88 \%$ ), and one was false positive.

A large recent prospective study from Poland (SowaStaszczak et al. 2016) assessed 99mTc-HYNIC-exendin-4 in 40 patients with hypoglycaemia and increased or confusing levels of serum insulin and C-peptide and negative or inconclusive results of prior imaging (including CT, MRI, EUS, and somatostatin receptor scintigraphy). Twenty-eight focal lesions were identified of which 18 cases proceeded to surgery and had pathologically confirmed insulinoma. Of the 10 focal cases that did not proceed to surgery, four were ineligible for surgery and six were lost to follow-up. It is important to highlight that this is a diverse (but realistic) study population evaluating both challenging cases of hypoglycaemia and inconclusive imaging studies. Consequently, it is expected that a significant proportion of cases would not necessarily represent insulinoma, and indeed of the remaining 12 patients with negative scans, two cases of factitious hypoglycaemia due to Munchausen syndrome were subsequently identified. In our experience, cases of clinically suspected nesidioblastosis or PGBH are often referred for GLP-1R imaging to exclude a potentially treatable focal insulinoma (given the limitations of available investigations), rather than localisation of definite insulinoma. As discussed earlier, insulinoma may potentially co-exist with nesidioblastosis and in one previously reported case of suspected nesidioblastosis, a synchronous insulinoma was clearly identified with GLP-1R molecular imaging with high management impact (Sowa-Staszczak et al. 2013). Confident localisation of co-existent insulinoma in this setting is an important 
potential role of molecular imaging in the evaluation of clinically suspected nesidioblastosis and PGBH.

Despite these favourable results, a small randomised cross-over pilot study in four non-localised cases of suspected insulinoma despite CT/MRI underwent imaging with both ${ }^{111}$ In-DTPA-exendin-4 SPECT/CT and ${ }^{68} \mathrm{Ga}$-DOTA-exendin-4 PET/CT; an insulinoma was successfully localised in all four cases with PET/CT but only $2 / 4$ cases were localised with SPECT/CT. There are also case reports of patients with extensive prior investigation including either negative ${ }^{111}$ In-DTPA-exendin- 4 or ${ }^{99 m}$ TcHYNIC-exendin-4 SPECT/CT with subsequent localisation on ${ }^{68} \mathrm{Ga}$-DOTA-exendin-4 (Cuthbertson et al. 2016) and ${ }^{68}$ Ga-NOTA-exendin-4 (Luo et al. 2015) respectively, highlighting the clinical importance of the superior spatial resolution PET compared to SPECT. Other advantages include lower radiation dose, faster acquisition time, and greater patient convenience due to imaging at $1 \mathrm{~h}$ post injection with the ${ }^{68} \mathrm{Ga}$-exendin-4 PET tracers.

A large prospective cohort study was recently published (Luo et al. 2016) evaluating imaging with ${ }^{68}$ Ga-NOTA-exendin-4 in 52 patients with endogenous hyperinsulinaemic hypoglycaemia. Forty-two of 43 histopathologically confirmed insulinomas included in the analysis were correctly localised with ${ }^{68} \mathrm{Ga}$-NOTAexendin-4, resulting in a sensitivity of $97.7 \%$. The sensitivities of CT, MRI, EUS, and 99mTc-HYNIC-TOC (somatostatin receptor scintigraphy) were $74.4 \%$ (32/43), 56.0\% (14/25), 84.0\% (21/25) and 19.5\% (8/41), respectively. Notably ${ }^{68} \mathrm{Ga}-\mathrm{NOTA}$-exendin-4 successfully localised multiple (five) small insulinomas in two patients with confirmed diagnosis of MEN1. The one false negative case was a $46 \mathrm{~mm}$ G2 tumour in the pancreatic tail that was photopaenic on ${ }^{68} \mathrm{Ga}$-NOTA-exendin-4, but consistent with previous studies it was intensely SSTR avid using ${ }^{99 \mathrm{~m} T c-}$ HYNIC-TOC SPECT/CT, clearly identified on CT and MRI and also mildly FDG avid (SUVmax 2.6) consistent with a more aggressive phenotype. Of the nine patients that did not undergo surgical intervention, three had focal lesions consistent with insulinoma but declined surgery, two had longstanding hypoglycaemia and glucokinase mutations consistent with congenital hyperinsulinism, two had clinical diagnosis of nesidioblastosis (one with NIPHS and another post-gastric bypass surgery) and a definite diagnosis was not established in the remaining two.

The high background renal uptake may limit the ability to detect small insulinoma in the adjacent distal pancreas. However, delayed scans were acquired $2-3 \mathrm{~h}$ after injection in 12 patients with favourable results; in two patients this showed demarcation between the tail of the pancreas and left kidney only on late scans, whereas in another two patients the average and maximum SUVs of the tumour increased by over $100 \%$ on the late scans. Another similar case was described by Luo et al. in 2015. As the effective half-life of exendin-4 is longer in tumours than in kidneys (Christ et al. 2009), it is recommended that patients who have negative results undergo further imaging $2-3 \mathrm{~h}$ after injection. A case with focal uptake contiguous with the adjacent kidney is discussed in Fig. 5. Quantitative renal uptake reduction studies in a Rip1Tag2 mouse have demonstrated significant reduction in renal activity using infusion of L-polyglutamic acid or gelofusine, with best results seen after a combination of both (Wild et al. 2010). Delayed imaging is likely satisfactory for diagnostic studies. However co-administration of renoprotective agents would be important to limit renal dose for the GLP-1R-targeted radionuclide therapy although the likelihood of significant GLP-1R expression is reduced in this setting and the potential for causing profound reactive hypoglycaemia must be considered.

Several series have described imaging findings consistent with nesidioblastosis (Christ et al. 2013,
A

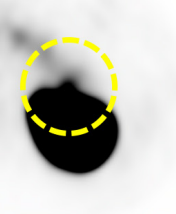

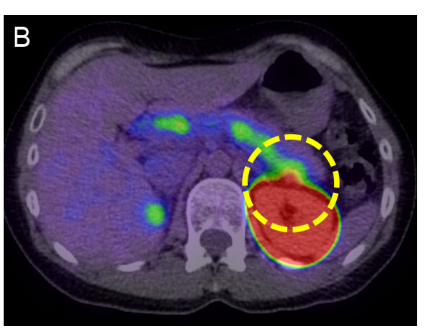

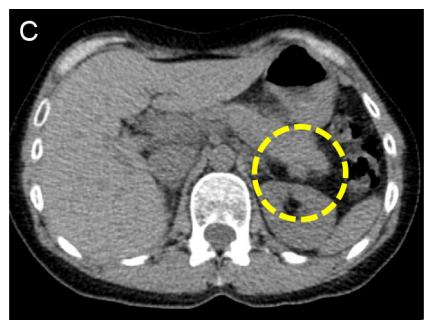

D

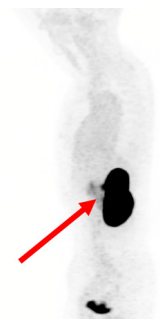

Figure $\mathbf{5}$

A 59-year-old woman with endogenous hyperinsulinaemic hypoglycaemia referred for ${ }^{68} \mathrm{Ga}$-DOTA-exendin-4 PET/CT for insulinoma localisation. Axial PET images (A) demonstrate focal intense uptake extending from the anterior margin of the left kidney (yellow circles), corresponding to an exophytic density arising from the pancreatic tail on fused PET/CT (B) and low dose CT (C) images. The lesion is also evident on sagittal PET maximum intensity projection (D). A 2-cm insulinoma (Grade 1, Ki-67 1\%) was subsequently enucleated from this site.

http://erc.endocrinology-journals.org DOI: 10.1530/ERC-17-0005
๑) 2017 Society for Endocrinology Printed in Great Britain
Published by Bioscientifica Ltd 
A

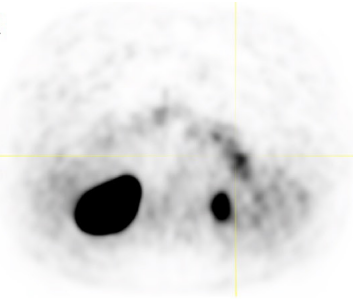

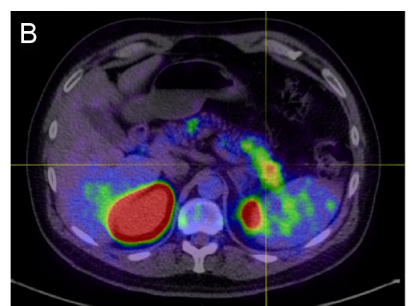

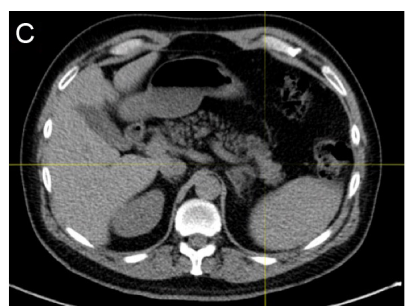

$\mathrm{D}$

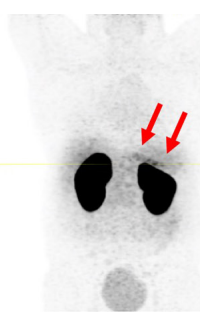

Figure 6

A 60-year-old man with refractory post-prandial hypoglycaemia following previous gastric surgery referred for ${ }^{68}$ Ga-DOTA-exendin- 4 PET/CT to exclude insulinoma. Axial PET images (A) demonstrate diffuse uptake in the pancreatic tail (SUVmax 8.7), without focal anatomic correlate in this region on fused PET/CT (B) and low dose CT (C) images. This diffuse uptake is also evident (red arrows) on the coronal PET maximum intensity projection (D). Dietary modification and conservative medical management was continued.

Luo et al. 2016, Sowa-Staszczak et al. 2016), and a case report described increased diffuse uptake from the tail from the pancreas to the pancreatic corpus (SUVmax 6.9) corresponding to a threefold increasein GLP-1Rsassociated with nesidioblastosis at this site on autoradiography. However, molecular imaging diagnostic criteria such as a reference range for GLP-1R uptake or typical patterns have not been described. Furthermore, prospective studies assessing the management impact from GLP-1Rdirected pancreatic resection for nesidioblastosis have not yet been performed despite this approach having theoretical merit. Consequently, the value of GLP-1R molecular imaging beyond excluding an insulinoma or, conversely, finding an unexpected insulinoma in the setting of clinically suspected nesidioblastosis has not yet been clearly defined. Figure 6 demonstrates diffusely increased uptake in the pancreatic tail in a case of suspected nesidioblastosis following gastric surgery (SUVmax 8.7). This is considered an abnormal distribution of radiotracer given the expected relative reduction in the density of beta-cells in the pancreatic tail compared to the head.

\section{FDG}

The enhanced uptake of glucose (and its analogue FDG) by cancer cells due to inefficient aerobic glycolysis, termed the Warburg effect (Warburg 1956), is the hallmark of in vivo cancer imaging with FDG PET/CT. Use of FDG PET/CT for the investigation and management of hypoglycaemic syndromes is limited to the subset of patients with metastatic insulinoma, where its use has expanded beyond a simple diagnostic/staging investigation to recognition of its powerful prognostic

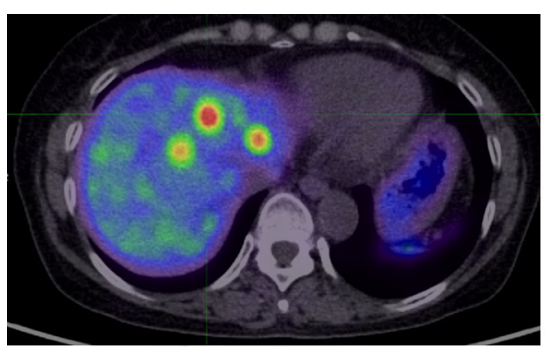

A

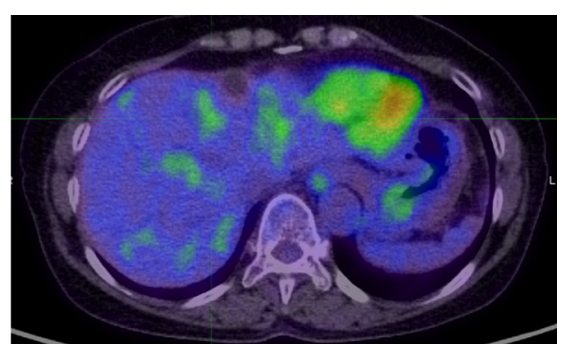

B
Figure 7

A 62-year-old woman with persistent hypoglycaemia referred for (A) ${ }^{68} \mathrm{Ga}$-DOTATATE and (B) FDG PET/CT for staging and assessment of suitability for peptide receptor radionuclide therapy. Upper images demonstrate fused axial $\mathrm{PET} / \mathrm{CT}$ with intense multifocal ${ }^{8} \mathrm{Ga}$-DOTATATE (left) and concordant mildly FDG (right) avid liver lesions. Note that FDG PET maximum intensity projection (lower right) demonstrates intense cardiac uptake, but no significant skeletal muscle activity despite presence of hyperinsulinism. 
ability to guide treatment and determine suitability for PRRT (Pattison \& Hofman 2015). At our institution, the indications for FDG PET/CT in context of metastatic NET are listed below:

- Patients with Ki-67 greater than or equal to $5 \%$.

- Patients with clinical or imaging findings of progressive disease within a period of 6 months.

- Patients with sites of disease identified on CT, which do not have uptake on SSTR PET/CT and are concerning for sites of poorly differentiated disease.

Diffusely increased skeletal muscle FDG uptake has been previously reported in the setting of insulinoma (Kamaleshwaran et al. 2010) presumably due to insulin stimulated overexpression of GLUT4 and hexokinase II in skeletal muscle. However, in our experience this complication does not occur as commonly as expected, potentially due a saturated intracellular glycogen pool resulting from chronic hyperinsulinaemia. However, case reports still describe clinically relevant findings on FDG PET/CT in this context and it should not be viewed as a contraindication (Kamaleshwaran et al. 2010, Belissant Benesty et al. 2016). Figure 7 demonstrates concordant SSTR +/FDG + uptake in a patient with metastatic insulinoma (Ki-67 20\%) with multifocal hepatic metastases. Of greater concern is the challenge of patient fasting while at a risk of hypoglycaemia, and it is recommended that patients are monitored carefully during the fasting period.

\section{Management of insulinoma}

Initial management of insulinoma involves symptomatic therapy, including oral carbohydrate supplementation, or intravenous/nasogastric glucose infusion depending upon the severity and duration of hypoglycaemia. Medical treatments are available for patients either waiting for surgery or not suitable for, failed or have refused surgical management. These include diazoxide, which inhibits insulin release by opening the ATP-dependent potassium channel in pancreatic beta-cells, somatostatin analogues to inhibit insulin secretion, and glucocorticoids in cases of refractory hypoglycaemia to inhibit insulin release and increase peripheral insulin resistance. It is notable that somatostatin analogues (particularly longacting formulations) may cause paradoxical worsening of hypoglycaemia due to the suppression of counterregulatory hormones such as glucagon and growth hormone (Healy et al. 2007, Abell et al. 2015).

\section{Surgery}

Confident preoperative localisation is necessary for successful surgical resection, the preferred treatment for benign insulinoma with recurrence rates of approximately $10 \%$ after follow-up for 10 years (Nikfarjam et al. 2008). Tumour enucleation using either an open or laparascopic approach is favoured in sporadic cases, however patients with MEN1 are at greater risk of relapse due to risk of malignancy and multiplicity (Crippa et al. 2012). Consequently, the choice of optimal surgical approach in patients with MEN1 needs to balance the potential for long-term cure with partial/total pancreatectomy, or enucleation of all insulinomas due to the lower morbidity.

\section{Local regional ablative therapy}

Alternative local regional treatments are increasingly available for patients at high surgical risk or those refusing surgery. These include ultrasound-guided ethanol ablation, selective chemoembolisation or transcutaneous/ laparascopic radiofrequency ablation (Davi et al. 2017). Although favourable outcomes have been reported in case reports or small series, the follow-up of these patients is typically $<1$ year, with longer term outcomes needed to validate these novel approaches.

\section{Tyrosine kinase inhibitors}

There are limited treatment options for metastatic insulinoma with intractable hypoglycaemia in which the cause of death is often hypoglycaemia rather than oncologic disease burden. Most evidence regarding treatment options of this rare tumour is extrapolated from literature for metastatic pancreatic NETs. Randomised placebo-controlled trials have demonstrated modest prolongation of progression-free survival (PFS) of 4.6 vs 11.0 months with everolimus (Yao et al. 2011) and 5.5 vs 11.4 months on sunitinib (Raymond et al. 2011) in patients with a range of well-differentiated pancreatic NET, albeit with some toxicity. Importantly, hyperglycaemia is a common side effect of everolimus, which makes it uniquely suitable for treatment of patients with hypoglycaemia secondary to metastatic insulinoma. A series of four patients requiring aggressive management of hypoglycaemia had substantial improvement in glycemic control after treatment with everolimus (Kulke et al. 2009). The mechanism of improved glycaemic control in this setting is uncertain, but direct antitumour effect of 
the drug, suppression of insulin production and release due to mTOR inhibition downstream of insulin receptors, and increased peripheral insulin resistance by impairment of AKT activation and signalling through the insulinreceptor substrate pathway likely play a role.

\section{Chemotherapy}

It is also worth mentioning the diabetogenic alkylating agent streptozocin, which has a well-established role combined with infusional 5-fluorouracil for treatment of advanced pancreatic NETs (Moertel et al. 1980) and numerous case reports have also demonstrated favourable results in patients with metastatic insulinoma (Gefel et al. 1975).

\section{Peptide receptor radionuclide therapy}

There is increasing evidence supporting the efficacy of PRRT using radiolabelled somatostatin agonists for the management of gasteroenteropancreatic NETs. The recently published results of the NETTER- 1 study, a phase III randomised controlled trial comparing octreotide LAR $30 \mathrm{mg}+{ }^{177} \mathrm{Lu}$-DOTATATE PRRT vs octreotide LAR $60 \mathrm{mg}$ in patients with progressive metastatic midgut NETs, did not reach a median PFS after $>30$-months follow-up in the PRRT arm compared to only 8.4 months in the control arm (Strosberg et al. 2017). The evidence base for PRRT in metastatic pancreatic NETs is limited to numerous large consecutive series. Ezzidin et al. analysed 68 patients with Grade 1 or 2 progressive advanced pancreatic NETs treated with ${ }^{177} \mathrm{Lu}$-DOTATATE resulting in PFS of 34 months, with reversible Grade 3 or more haematotoxicity in 5.9\% and no significant nephrotoxicity (Ezziddin et al. 2014). A series of 52 patients with metastatic FDG avid (predominantly Grade 2) GEP NET from our institution treated with ${ }^{177} \mathrm{Lu}$-DOTATATE combined with radiosensitising 5-fluorouracil chemotherapy demonstrated PFS of 48 months with negligible Grade 3 or 4 toxicities (Kashyap et al. 2015). Our practice has favoured treatment with PRRT for suitable patients given the markedly greater PFS compared to other available therapies and its minimal toxicity. One small case series (van Schaik et al. 2011) and several case reports (Costa et al. 2013, Abell et al. 2015) have also confirmed excellent symptomatic response with resolution of hypoglycaemia in patients with metastatic insulinoma. However, the risk of transient worsening of hormonal symptoms after treatment of functional NETs with PRRT is well recognised. In a series of 479 patients treated with PRRT, 1\% required prolonged hospitalisation for exacerbation of severe associated hormonal symptoms. Hypoglycaemia symptomatic therapies are required as described above, often in combination and for prolonged periods with appropriate supportive care given the often favourable delayed symptomatic response from PRRT.

Patients at our institution are selected for treatment with PRRT according to the suggested criteria in Table 2. In particular, treatment is based upon demonstration of SSTR-tracer uptake greater than the liver uptake at all sites of disease that are not below the spatial resolution of the imaging technique used and therefore subject to partial volume effects. It is fortunate from a theranostics perspective that the majority of cases with metastatic insulinoma express SSTR to facilitate PRRT (Wild et al. 2011) although disease heterogeneity with the presence of FDG +/SSTR - and FDG -/SSTR + sites of disease may occur (Belissant Benesty et al. 2016) such as described in Fig. 8. Confirmed progressive disease within 12 months or refractory hormonal symptoms (such as hypoglycaemia) despite maximal medical therapy is a requirement for treatment at our institution. Such clarification of the therapeutic goal is important because PRRT may still provide effective control of hypoglycaemia cases with disease heterogeneity by targeting all sites of SSTR avid well-differentiated insulin-producing disease.

Table 2 PRRT treatment criteria and contraindications at Peter MacCallum Cancer Centre.

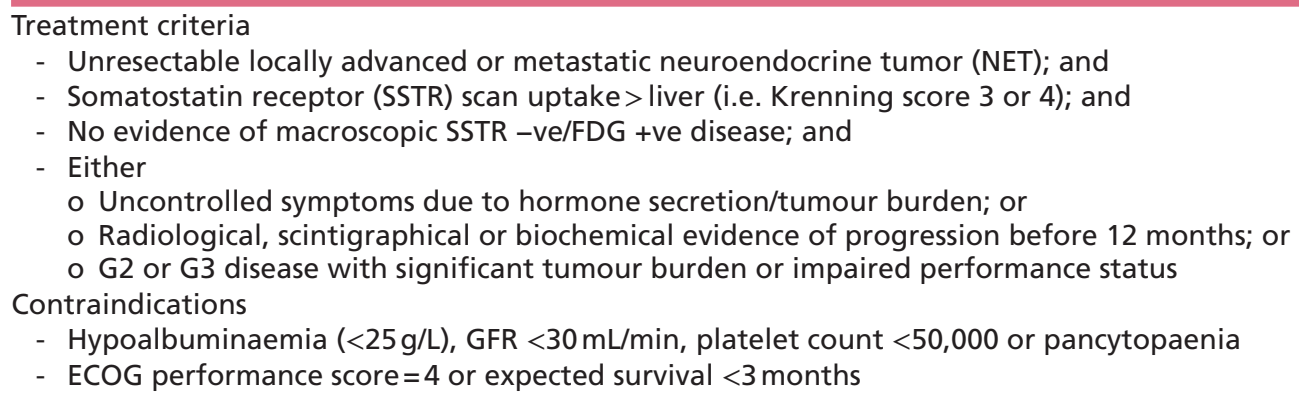




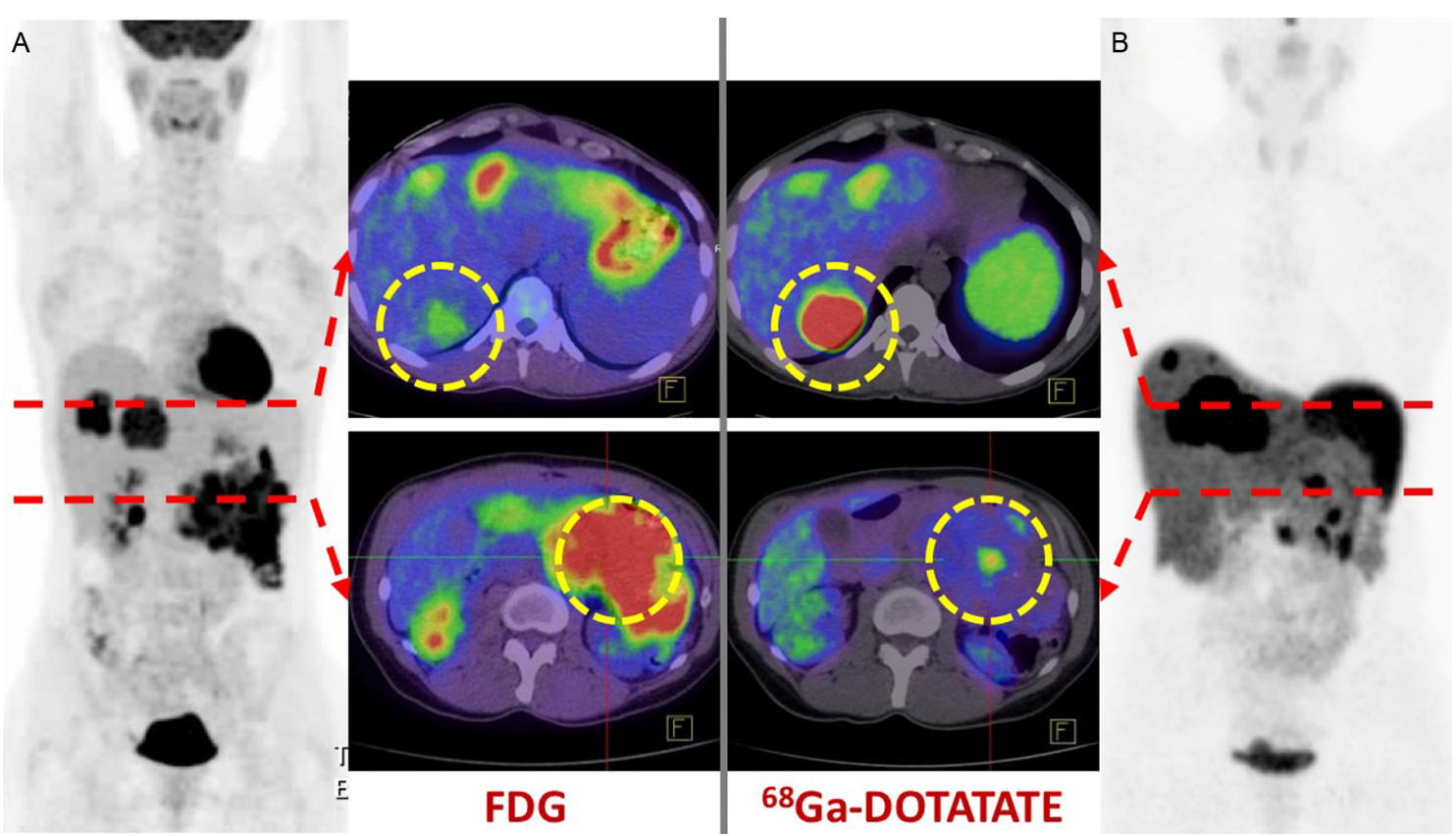

Figure 8

A 46-year-old woman with refractory hypoglycaemia associated with metastatic insulinoma was referred for (A) FDG and (B) 68Ga-DOTATATE PET/CT to assess suitability for peptide receptor radionuclide therapy (PRRT). Fused axial PET/CT through the upper liver (upper images) demonstrates predominantly ${ }^{68} \mathrm{Ga}$-DOTATATE avid hepatic lesions whilst fused axial PET/CT images through the pancreas (lower images) demonstrate a bulky, discordantly FDG-avid primary site. Whilst PRRT may be effective to control symptoms of hypoglycaemia, this molecular imaging phenotype demonstrates that additional therapy is required to treat the extensive discordantly FDG-avid sites of disease.

Although combination therapy with everolimus and PRRT is an attractive option (Claringbold \& Turner 2015), there have been conflicting results from this combination in preclinical studies, including a worse outcome with dual-therapy than PRRT alone (Johnbeck et al. 2012, Bison et al. 2014). These results suggest that a cautious approach is prudent until these findings are better understood.

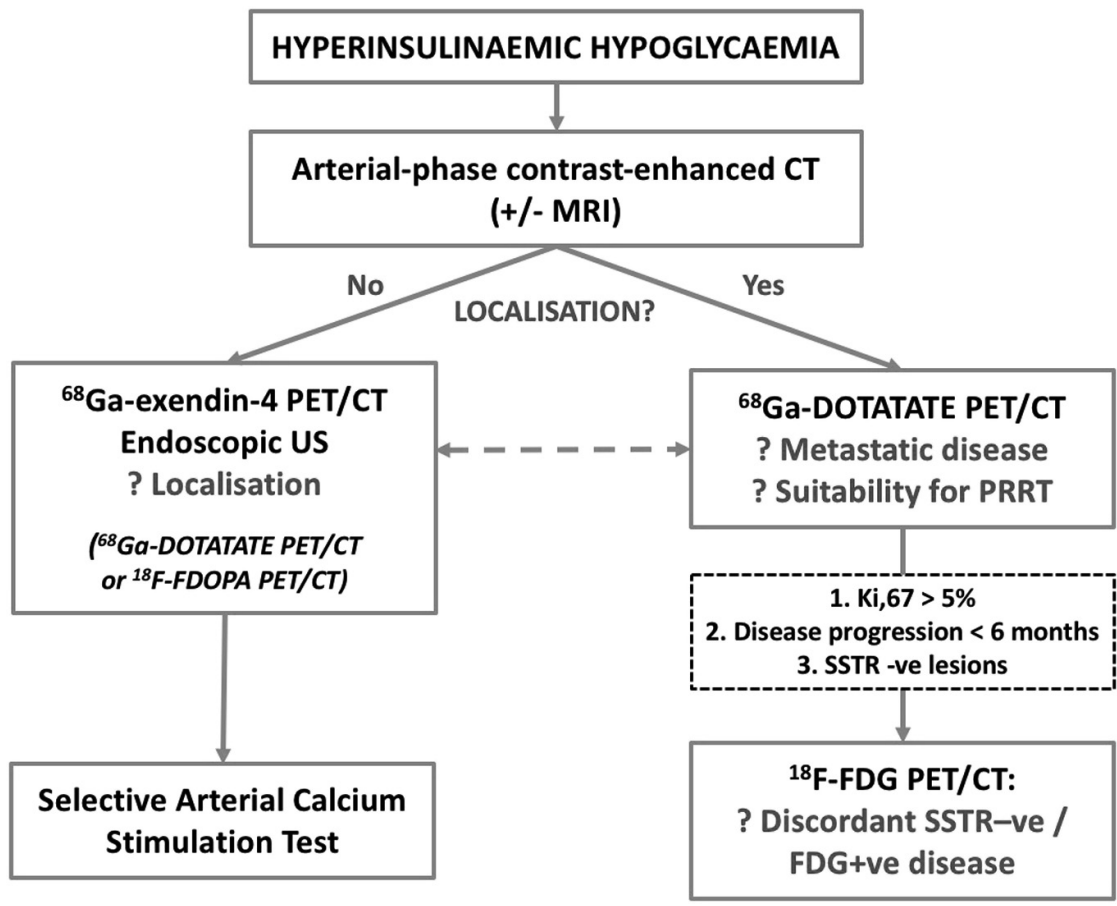

\section{Figure 9}

Suggested approach to molecular imaging of endogenous hyperinsulinaemic hypoglycaemia. The role of this diagnostic pathway includes localisation of potentially resectable insulinoma, assessment of suitability for treatment with PRRT in cases with unresectable metastatic disease and exclusion of insulinoma in cases of suspected nesidioblastosis and post-gastric bypass hypoglycaemia. 


\section{Approach to molecular imaging for hypoglycaemia}

It is fortunate that the biological and molecular imaging characteristics of insulinoma are uniquely aligned with the available treatment options, allowing a rational diagnostic approach to insulinoma localisation and therapeutic planning outlined in Fig. 9. Following initial clinical and biochemical diagnosis of endogenous hyperinsulinaemic hypoglycaemia, a triple phase contrast enhanced CT of the abdomen (with particular attention to the arterial phase fine slice images of the pancreas) or MRI is recommended. If no obvious lesion is identified at this point, further assessment for localisation of presumed benign insulinoma is recommended. Exclusion of benign insulinoma should also be considered in the setting of post-prandial hypoglycaemia due to suspected nesidioblastosis or PGBH. Given that benign insulinoma has near ubiquitous expression of the GLP-1R, imaging with radiolabelled-exendin-4 (particularly ${ }^{68}$ Ga-NOTA-exendin-4) is recommended to provide confident localisation. However, it must be recognised that this test is not commercially available in kit form and requires on-site radiopharmaceutical synthesis. Consequently, there is currently limited access to this tracer outside of research institutions in Europe, Australia, and China. No commercial product is currently available to ascertain indicative costs. Depending upon radiotracer availability or local expertise, other appropriate localisation techniques at this point include EUS, ${ }^{68}$ Ga-DOTATATE PET/CT (widely available at academic centres in Europe and Australia, with improving access within the United States) or 18F-FDOPA PET/CT with carbidopa premedication. In particular, if GLP-1R imaging is negative (including delayed imaging at $2-3 \mathrm{~h}$ ) then imaging with ${ }^{68} \mathrm{Ga}$-DOTATATE is recommended as, to date, nearly all reported insulinomas have been localised with one or other of these tests. Finally, more invasive SACST is recommended only if there is ongoing clinical suspicion and non-localisation. However, if the initial CT scan identifies an obvious insulinoma or concern regarding metastatic disease, further evaluation with ${ }^{68} \mathrm{Ga}$-DOTATATE PET/CT (or other somatostatin receptor imaging) is recommended for accurate preoperative staging and to assess suitability for PRRT in the presence of inoperable metastatic disease. There are several indications for FDG PET/CT in the setting of metastatic disease described in FDG section.

\section{Future hypoglycaemia imaging research}

Study design is an important consideration when considering the evidence base for novel molecular imaging tracers described in this review. Prospective study designs are clearly preferable, ensuring rigorous data collection and minimisation of selection bias, yet are rarely performed for rare tumours such as insulinoma. Retrospective reviews are susceptible to selection bias, in this context particularly the referral of challenging cases not localised by conventional means or with a predominance of metastatic cases that may have different molecular imaging characteristics to the most common benign tumours. Of greatest concern is the impact of partial verification bias when histopathology is used as the gold standard, as is the case with most reported studies. In these circumstances, the result of the index test (localisation study) is the basis for verification by surgical excision and histopathologic evaluation. Depending on the institutional referral patterns and available investigations, this may lead to a significant overestimation of investigation sensitivity, because all non-localised cases will be excluded from analysis. There are various study designs to tackle this issue, including prospective registration of all cases through case registries, utilisation of additional localisation strategies, use of a composite gold standard that includes durable follow-up of patient outcome and also reporting of all non-localised cases. Owing to the rarity of this condition, multicentre trials are likely to be required to determine the most cost-efficient diagnostic paradigm. We believe that a randomised cross-over design would provide robust evidence to guide diagnostic pathways in this regard. In the trial design, patients with likely insulinoma based on laboratory testing would be randomised to either a conventional paradigm of EUS and SACST or molecular imaging to test the independent utility of each approach. If disease location remained occult after the first-line investigation, patients would cross-over to the alternative diagnostic approach to assess the incremental value of the second-line investigations. This design can also include health economic analyses, safety and patient preference evaluations.

\section{Conclusion}

There has been significant recent progress in molecular imaging for the investigation of adult non- 
diabetic hypoglycaemic syndromes, targeting GLP-1R (68Ga-exendin-4), SSTR (68Ga-DOTATATE), the APUD system (18F-FDOPA), and glyclolytic metabolism (18F-FDG) for localisation and in vivo disease characterisation. Although currently limited to use in research centres in Europe, Australia and China, ${ }^{68}$ Ga-exendin-4 enables accurate localisation of benign insulinoma in cases of endogenous hyperinsulinaemic hypoglycaemia, and has an emerging role excluding insulinoma in cases of suspected nesidioblastosis or PGBH. Although metastatic insulinoma is a rare component of what is itself a rare disease, it poses significant diagnostic and management challenges. An understanding of the causes of hypoglycaemia, its investigation and management provides a context for those involved in the care of endocrine-related cancers to manage this entity for which there is currently a rather limited evidence base. Although everolimus may help to control symptoms and delay disease progression by several months on an average, further evaluation of the role of PRRT in both controlling excess hormonal activity and disease progression is warranted. Since most malignant insulinomas seems to express SSTR2, well-established agents including ${ }^{177} \mathrm{Lu}$-DOTATATE, are a logical starting point for prospective evaluation but will likely require cooperation between a number of centres seeing a high volume of neuroendocrine tumours. It remains to be seen if PRRT using GLP-1R ligands will be a feasible option for treating unresectable insulinoma that lack SSTR2 expression but have adequate uptake of diagnostic tracers targeting this receptor.

\section{Declaration of interest}

The authors declare that there is no conflict of interest that could be perceived as prejudicing the impartiality of this review.

\section{Funding}

Professor Hicks' research is supported by an Australian National Health and Medical Research Foundation Practitioner Fellowship (NHMRC APP1108050).

\section{Acknowledgements}

The authors are grateful for the invaluable assistance of Peter Eu (our radiopharmacist), our dedicated nuclear medicine technologists and nursing staff in caring for these patients and network of referring endocrinologists and endocrine surgeons.

\section{References}

Abell SK, Teng J, Dowling A, Hofman MS, MacIsaac RJ \& Sachithanandan N 2015 Prolonged life-threatening hypoglycaemia following dose escalation of octreotide LAR in a patient with malignant polysecreting pancreatic neuroendocrine tumour.
Endocrinology, Diabetes and Metabolism Case Reports 2015 article 140097. (doi:10.1530/edm-14-0097)

Ajala ON, Huffman DM \& Ghobrial II 2016 Glucokinase mutation - a rare cause of recurrent hypoglycaemia in adults: a case report and literature review. Journal of Community Hospital Internal Medicine Perspectives 6 32983. (doi:10.3402/jchimp.v6.32983)

Antwi K, Fani M, Nicolas G, Rottenburger C, Heye T, Reubi JC, Gloor B, Christ E \& Wild D 2015 Localization of hidden insulinomas with 68Ga-DOTA-exendin-4 PET/CT: a pilot study. Journal of Nuclear Medicine 56 1075-1078. (doi:10.2967/jnumed.115.157768)

Barthlen W, Blankenstein O, Mau H, Koch M, Hohne C, Mohnike W, Eberhard T, Fuechtner F, Lorenz-Depiereux B \& Mohnike K 2008 Evaluation of [18F]fluoro-L-DOPA positron emission tomography computed tomography for surgery in focal congenital hyperinsulinism. Journal of Clinical Endocrinology and Metabolism 93 869-875. (doi:10.1210/jc.2007-2036)

Belissant Benesty O, Cassou-Mounat T, Vatier C, Talbot JN \& Montravers F 2016 Tumour heterogeneity detected by $68 \mathrm{Ga}$ DOTATOC and 18F-FDG PET/CTs in one malignant insulinoma with involvement of the portal splenic confluence and ovarian metastases. Clinical Nuclear Medicine 41 874-876. (doi:10.1097/ RLU.0000000000001360)

Bison SM, Pool SE, Koelewijn SJ, van der Graaf LM, Groen HC, Melis M \& de Jong M 2014 Peptide receptor radionuclide therapy (PRRT) with [(177)Lu-DOTA(0), Tyr(3)] octreotate in combination with RAD001 treatment: further investigations on tumor metastasis and response in the rat pancreatic CA20948 tumor model. EJNMMI Research 4 21. (doi:10.1186/s13550-014-0021-y)

Bright E, Garcea G, Ong SL, Madira W, Berry DP \& Dennison AR 2008 An unusual case of concurrent insulinoma and nesidioblastosis. Journal of the Pancreas 9 649-653.

Christ E, Wild D, Ederer S, Béhé M, Nicolas G, Caplin ME, Brändle M, Clerici T, Fischli S, Stettler C, et al. 2013 Glucagon-like peptide-1 receptor imaging for the localization of insulinomas: a prospective multicentre imaging study. Lancet Diabetes and Endocrinology $\mathbf{1}$ 115-122. (doi:10.1016/S2213-8587(13)70049-4)

Christ E, Wild D, Forrer F, Brandle M, Sahli R, Clerici T, Gloor B, Martius F, Maecke H \& Reubi JC 2009 Glucagon-like peptide-1 receptor imaging for localization of insulinomas. Journal of Clinical Endocrinology and Metabolism 94 4398-4405. (doi:10.1210/jc.2009-1082)

Claringbold PG \& Turner JH 2015 NeuroEndocrine tumor therapy with lutetium-177-octreotate and everolimus (NETTLE): a phase I study. Cancer Biotherapy and Radiopharmaceuticals 30 261-269. (doi:10.1089/ cbr.2015.1876)

Costa R, Costa R, Bacchi CE \& Filho PA 2013 Metastatic insulinoma managed with radiolabeled somatostatin analog. Case Reports in Endocrinology 2013 252159. (doi:10.1155/2013/252159)

Crippa S, Zerbi A, Boninsegna L, Capitanio V, Partelli S, Balzano G, Pederzoli P, Di Carlo V \& Falconi M 2012 Surgical management of insulinomas: short- and long-term outcomes after enucleations and pancreatic resections. Archives of Surgery 147 261-266. (doi:10.1001/ archsurg.2011.1843)

Crona J, Norlen O, Antonodimitrakis P, Welin S, Stalberg P \& Eriksson B 2016 Multiple and secondary hormone secretion in patients with metastatic pancreatic neuroendocrine tumours. Journal of Clinical Endocrinology and Metabolism 101 445-452. (doi:10.1210/jc.20152436)

Cryer PE, Axelrod L, Grossman AB, Heller SR, Montori VM, Seaquist ER \& Service FJ 2009 Evaluation and management of adult hypoglycemic disorders: an endocrine society clinical practice guideline. Journal of Clinical Endocrinology and Metabolism 94 709-728. (doi:10.1210/jc.2008-1410)

Cuthbertson DJ, Banks M, Khoo B, Antwi K, Christ E, Campbell F, Raraty M \& Wild D 2016 Application of 68Ga-DOTA-exendin-4 PET/ CT to localize an occult insulinoma. Clinical Endocrinology $\mathbf{8 4}$ 789-791. (doi:10.1111/cen.12973) 
Davi MV, Pia A, Guarnotta V, Pizza G, Colao A \& Faggiano A 2017 The treatment of hyperinsulinaemic hypoglycaemia in adults: an update. Journal of Endocrinological Investigation 40 9-20. (doi:10.1007/s40618016-0536-3)

De Herder WW, Kwekkeboom DJ, Valkema R, Feelders RA, van Aken MO, Lamberts SW, van der Lely AJ \& Krenning EP 2005 Neuroendocrine tumors and somatostatin: imaging techniques. Journal of Endocrinological Investigation 28 132-136.

de Sa SV, Correa-Giannella ML, Machado MC, de Souza JJ, Pereira MA, Patzina RA, Siquiera SA, Machado MCC \& Giannella-Neto D 2006 Somatostatin receptor subtype 5 (SSTR5) mRNA expression is related to histopathological features of cell proliferation in insulinomas. Endocrine-Related Cancer 13 69-78. (doi:10.1677/erc.1.00962)

Druce MR, Muthuppalaniappan VM, O'Leary B, Chew SL, Drake WM, Monson JP, Akker SA, Besser M, Sahdev A, Rockall A, et al. 2010 Diagnosis and localisation of insulinoma: the value of modern magnetic resonance imaging in conjunction with calcium stimulation catheterisation. European Journal of Endocrinology 162 971-978. (doi:10.1530/EJE-10-0056)

Eriksson O, Velikyan I, Selvaraju RK, Kandeel F, Johansson L, Antoni G, Eriksson B, Sörensen J \& Korsgren O 2014 Detection of metastatic insulinoma by positron emission tomography with [68Ga] exendin-4 - a case report. Journal of Clinical Endocrinology and Metabolism 99 1519-1524. (doi:10.1210/jc.2013-3541)

Ezziddin S, Khalaf F, Vanezi M, Haslerud T, Mayer K, Al Zreiqat A, Willinek W, Biersack HJ \& Sabet A 2014 Outcome of peptide receptor radionuclide therapy with $177 \mathrm{Lu}$-octreotate in advanced grade $1 / 2$ pancreatic neuroendocrine tumours. European Journal of Nuclear Medicine and Molecular Imaging 41 925-933. (doi:10.1007/s00259013-2677-3)

Gefel A, Flatau E, Ayalon D, Papo J \& Loewenthal M 1975 Malignant metastatic insulinoma treated with streptozocin: report of a case and review of the literature. Clinical Endocrinology 4 461-468. (doi:10.1111/j.1365-2265.1975.tb01555.x)

Goldfine AB, Mun EC, Devine E, Bernier R, Baz-Hecht M, Jones DB, Schneider BE, Holst JJ \& Patti ME 2007 Patients with neuroglycopenia after gastric bypass surgery have exaggerated incretin and insulin secretory responses to a mixed meal. Journal of Clinical Endocrinology and Metabolism 92 4678-4685. (doi:10.1210/jc.2007-0918)

Guettier JM, Kam A, Chang R, Skarulis MC, Cochran C, Alexander HR, Libutti SK, Pingpank JF \& Gorden P 2009 Localization of insulinomas to regions of the pancreas by intraarterial calcium stimulation: the NIH experience. Journal of Clinical Endocrinology and Metabolism 94 1074-1080. (doi:10.1210/jc.2008-1986)

Guettier JM, Lungu A, Goodling A, Cochran C \& Gorden P 2013 The role of proinsulin and insulin in the diagnosis of insulinoma: a critical evaluation of the endocrine society clinical practice guideline. Journal of Clinical Endocrinology and Metabolism 98 4752-4758. (doi:10.1210/jc.2013-2182)

Healy ML, Dawson SJ, Murray RM, Zalcberg J \& Jefford M 2007 Severe hypoglycaemia after long-acting octreotide in a patient with an unrecognized malignant insulinoma. Internal Medicine Journal 37 406-409. (doi:10.1111/j.1445-5994.2007.01371.x)

Hofman MS \& Hicks RJ 2012 Changing paradigms with molecular imaging of neuroendocrine tumours. Discovery Medicine 14 71-81.

Hofman MS, Kong G, Neels OC, Eu P, Hong E \& Hicks RJ 2012 High management impact of Ga-68 DOTATATE (GaTate) PET/CT for imaging neuroendocrine and other somatostatin expressing tumours. Journal of Medical Imaging and Radiation Oncology 56 40-47. (doi:10.1111/j.1754-9485.2011.02327.x)

Ilias I, Shulkin B \& Pacak K 2005 New functional imaging modalities for chromaffin tumors, neuroblastomas and ganglioneuromas. Trends in Endocrinology \& Metabolism 16 66-72. (doi:10.1016/j. tem.2005.01.007)

Imperiale A, Sebag F, Vix M, Castinetti F, Kessler L, Moreau F, Bachellier P, Guillet B, Namer IJ, Mundler O, et al. 2015 18F-FDOPA
PET/CT imaging of insulinoma revisited. European Journal of Nuclear Medicine and Molecular Imaging 42 409-418. (doi:10.1007/s00259014-2943-z)

Johnbeck CB, Nielsen C, Knigge U \& Kjaer A 2012 Synergistic effect of combined treatment with ${ }^{177} \mathrm{Lu}$-DOTATATE and everolimus in neuroendocrine tumors as monitored by ${ }^{18}$ F-FDG-PET: studies in human neuroendocrine xenografts. Journal of Nuclear Medicine $\mathbf{5 3}$ abstract 57 .

Kamaleshwaran KK, Bhattacharya A, Chakraborty D, Manohar K \& Mittal BR 2010 Diffusely increased muscular uptake of [18F] fluorodeoxyglucose: a clue for the diagnosis of insulinoma? European Journal of Nuclear Medicine and Molecular Imaging 371800. (doi:10.1007/s00259-010-1515-0)

Kashyap R, Hofman MS, Michael M, Kong G, Akhurst T, Eu P, Zannino D \& Hicks RJ 2015 Favourable outcomes of 177Lu-octreotate peptide receptor chemoradionuclide therapy in patients with FDG-avid neuroendocrine tumours. European Journal of Nuclear Medicine and Molecular Imaging 42 176-185. (doi:10.1007/ s00259-014-2906-4)

Kauhanen S, Seppanen M, Minn H, Gullichsen R, Salonen A, Alanen K, Parkkola R, Solin O, Bergman J, Sane T, et al. 2007 Fluorine-18-Ldihydroxyphenylalanine (18F-DOPA) positron emission tomography as a tool to localize an insulinoma or B-cell hyperplasia in adult patients. Journal of Clinical Endocrinology and Metabolism 92 1237-1244. (doi:10.1210/jc.2006-1479)

Kiesewetter DO, Gao H, Ma Y, Niu G, Quan Q, Guo N \& Chen X 2012 18F-radiolabeled analogs of exendin-4 for PET imaging of GLP-1 in insulinoma. European Journal of Nuclear Medicine and Molecular Imaging 39 463-473. (doi:10.1007/s00259-011-1980-0)

Klöppel G, Perren A \& Heitz PU 2004 The gastroenteropancreatic neuroendocrine cell system and its tumors: the WHO classification. Annals of the New York Academy of Sciences 1014 13-27. (doi. org/10.1196/annals.1294.002)

Korner M, Stockli M, Waser B \& Reubi JC 2007 GLP-1 Receptor expression in human tumors and human normal tissues: potential for in vivo targeting. Journal of Nuclear Medicine 48 736-743. (doi:10.2967/jnumed.106.038679)

Kulke MH, Bergsland EK \& Yao JC 2009 Glycemic control in patients with insulinoma treated with everolimus. New England Journal of Medicine 360 195-197. (doi:10.1056/NEJMc0806740)

Krenning EP, Kwekkeboom DJ, Bakker WH, Breeman WA, Kooij PP, Oei HY, van Hagen M, Postema PT, de Jong M, Reubi JC, et al. 1993 Somatostatin receptor scintigraphy with [111In-DTPAD- Phe1]- and [123I-Tyr3]-octreotide: the Rotterdam experience with more than 1000 patients. European Journal of Nuclear Medicine 20 716-731. (doi:10.1007/BF00181765)

Lamberts SW, Bakker WH, Reubi JC \& Krenning EP 1990 Somatostatinreceptor imaging in the localization of endocrine tumors. New England Journal of Medicine 323 1246-1249. (doi:10.1056/ NEJM199011013231805)

Lee CJ, Wood GC, Lazo M, Brown TT, Clark JM, Still C \& Benotti P 2016 Risk of post-gastric bypass surgery hypoglycemia in nondiabetic individuals: a single center experience. Obesity 24 1342-1348. (doi:10.1002/oby.21479)

Lerche S, Soendergaard L, Rungby J, Moeller N, Holst JJ, Schmitz OE \& Brock B. 2009 No increased risk of hypoglycaemic episodes during $48 \mathrm{~h}$ of subcutaneous glucagon-like-peptide- 1 administration in fasting healthy subjects. Clinical Endocrinology 71 500-506. (doi:10.1111/j.1365-2265.2008.03510.x)

Luo Y, Yu M, Pan Q, Wu W, Zhang T, Kiesewetter DO, Zhu Z, Li F, Chen $\mathrm{X} \&$ Z Zhao Y 2015 68Ga-NOTA-exendin-4 PET/CT in detection of occult insulinoma and evaluation of physiological uptake. European Journal of Nuclear Medicine and Molecular Imaging 42 531-532. (doi:10.1007/s00259-014-2946-9)

Luo Y, Pan Q, Yao S, Yu M, Wu W, Xue H, Kiesewetter DO, Zhu Z, Li F, Zhao Y \& Chen X 2016 Glucagon-like peptide-1 receptor PET/CT 
with 68Ga-NOTA-exendin-4 for detecting localized insulinoma: a prospective cohort study. Journal of Nuclear Medicine 57 715-720. (doi:10.2967/jnumed.115.167445)

McLean A 2004 Endoscopic ultrasound in the detection of pancreatic islet cell tumors. Cancer Imaging 4 84-91. (doi:10.1102/14707330.2004.0008)

Meier JJ, Butler AE, Galasso R \& Butler PC 2006 Hyperinsulinemic hypoglycemia after gastric bypass surgery is not accompanied by islet hyperplasia or increased beta-cell turnover. Diabetes Care 29 1554-1559. (doi:10.2337/dc06-0392)

Meintjes M, Endozo R, Dickson J, Erlandsson K, Hussain K, Townsend C, Menezes L \& Bomanji J 2013 18F-DOPA PET and enhanced CT imaging for congenital hyperinsulinism: initial UK experience from a technologist's perspective. Nuclear Medicine Communications 34 601-608. (doi:10.1097/MNM.0b013e32836069d0)

Mikkola K, Yim CB, Fagerholm V, Ishizu T, Elomaa VV, Rajander J, Jurttila J, Saanijoki T, Tolvanen T, Tirri M, et al. $201464 \mathrm{Cu}-$ and 68Ga-labelled [Nle14,Lys40(Ahx-NODAGA)NH2]-exendin-4 for pancreatic beta cell imaging in rats. Molecular Imaging and Biology 16 255-263. (doi:10.1007/s11307-013-0691-2)

Moertel CG, Hanley JA \& Johnson LA 1980 Streptozocin alone compared with streptozocin plus fluorouracil in the treatment of advanced islet-cell carcinoma. New England Journal of Medicine $\mathbf{3 0 3}$ 1189-1194. (doi:10.1056/NEJM198011203032101)

Nikfarjam M, Warshaw AL, Axelrod L, Deshpande V, Thayer SP, Ferrone CR \& Fernández-del Castillo C 2008 Improved contemporary surgical management of insulinomas: a 25-year experience at the Massachusetts General Hospital. Annals of Surgery 247 165-172. (doi:10.1097/SLA.0b013e31815792ed)

Nockel P, Babic B, Millo C, Herscovitch P, Patel D, Nilubol N, Sadowski S, Cochran C, Gorden P \& Kebebew E 2017 Localisation of insulinoma using 68Ga-DOTATATE PET/CT scan. Journal of Clinical Endocrinology and Metabolism 102 195-199. (doi.org/10.1210/jc.20163445)

Oberg K \& Eriksson B 2005 Endocrine tumours of the pancreas. Best Practice and Research: Clinical Gastroenterology 19 753-781. (doi:10.1016/j.bpg.2005.06.002)

Otonkoski T, Nanto-Salonen K, Seppanen M, Veijola R, Huopio H, Hussain K, Tapanainen P, Eskola O, Parkkola R, Ekstrom K, et al. 2006 Noninvasive diagnosis of focal hyperinsulinism of infancy with [18F]DOPA positron emission tomography. Diabetes 55 13-18. (doi:10.2337/diabetes.55.01.06.db05-1128)

Paiva ES, Pereira AE, Lombardi MT, Nishida SK, Tachibana TT, Ferrer C, Hauache OM, Vieira JG \& Reis AF 2006 Insulin autoimmune syndrome (Hirata disease) as differential diagnosis in patients with hyperinsulinaemic hypoglycaemia. Pancreas 32 431-432. (doi:10.1097/01.mpa.0000220872.18153.72)

Patti ME, McMahon G, Mun EC, Bitton A, Holst JJ, Goldsmith J, Hanto DW, Callery M, Arky R, Nose V, et al. 2005 Severe hypoglycaemia post-gastric bypass requiring partial pancreatectomy: evidence for inappropriate insulin secretion and pancreatic islet hyperplasia. Diabetologia 48 2236-2240. (doi:10.1007/s00125-005-1933-x)

Patti ME \& Goldfine A 2014 Hypoglycaemia after gastric bypass: the dark side of GLP-1. Gastroenterology 146 605-608. (doi:10.1053/j. gastro.2014.01.038)

Patti ME, Li P, Goldfine AB 2015 Insulin response to oral stimuli and glucose effectiveness increased in neuroglycopenia following gastric bypass. Obesity 23 798-807. (doi:10.1002/oby.21043)

Pattison DA \& Hofman MS 2015 Role of fluorodeoxyglucose PET/ computed tomography in targeted radionuclide therapy for endocrine malignancies. PET Clinics 10 461-476. (doi:10.1016/j. cpet.2015.05.005)

Placzkowski KA, Vella A, Thompson GB, Grant CS, Reading CC, Charboneau JW, Andrews JC \& Lloyd RV. Service FJ 2009 secular trends in the presentation and management of functioning insulinoma at the Mayo Clinic, 1987-2007. Journal of Clinical
Endocrinology and Metabolism 94 1069-1073. (doi:10.1210/jc.20082031)

Prasad V, Sainz-Esteban A, Arsenic R, Plockinger U, Denecke T, Pape UF, Pascher A, Kuhnen P, Pavel M \& Blankenstein O 2016 Role of ${ }^{68} \mathrm{Ga}$ somatostatin receptor PET/CT in the detection of endogenous hyperinsulinaemic focus: an explorative study. European Journal of Nuclear Medicine and Molecular Imaging 43 1593-1600. (doi:10.1007/ s00259-016-3331-7)

Raymond E, Dahan L, Raoul JC, Bang YJ, Borbath I, Lombard-Bohas C, Valle J, Metrakos P, Smith D, Vinik A, et al. 2011 Sunitinib malate for the treatment of pancreatic neuroendocrine tumors. New England Journal of Medicine 364 501-513. (doi:10.1056/NEJMoa1003825)

Reubi JC, Perren A, Rehmann R, Waser B, Christ E, Callery M, Goldfine AB \& Patti ME 2010 Glucagon-like peptide-1 (GLP-1) receptors are not overexpressed in pancreatic islets from patients with severe hyperinsulinaemic hypoglycaemia following gastric bypass. Diabetologia 53 2641-2645. (doi:10.1007/s00125-010-1901-y)

Reubi JC \& Waser B 2003 Concomitant expression of several peptide receptors in neuroendocrine tumors as molecular basis for in vivo multireceptor tumor targeting. European Journal of Nuclear Medicine 30 781-793. (doi:10.1007/s00259-003-1184-3)

Ruby RJ, Armato JP, Pyke C \& Peters AL 2014 GLP-1 provoked severe hypoglycemia in an individual with type 2 diabetes and a benign insulinoma. Diabetes Care 37 e177-e178. (doi:10.2337/dc14-0514)

Sadowski SM, Neychev V, Cottle-Delisle C, Merkel R, Yang LA, Quezado MM, Chang R \& Kebebew E 2014 Detection of insulinoma using 68Gallium-DOTATATE PET/CT: a case report. Gland Surgery 3 E1-E5. (doi:10.3978/j.issn.2227-684X.2014.10.02)

Sadoski SM, Millo C, Cottle-Delisle C, Merkel R, Yang LA, Herscovitch P, Pacak K, Simonds WF, Marx SJ \& Kebebew E 2015 68GalliumDOTATATE PET/CT scanning results in patients with MEN1. Journal of the American College of Surgeons 221 509-517. (doi:10.1016/j. jamcollsurg.2015.04.005)

Salehi M, Gastaldelli A \& D'Alessio DA 2014 Altered islet function and insulin clearance cause hyperinsulinemia in gastric bypass patients with symptoms of postprandial hypoglycemia. Journal of Clinical Endocrinology and Metabolism 99 2008-2017. (doi:10.1210/jc.20132686)

Santhanam P \& Taieb D 2014 Role of 18F-FDOPA PET/CT imaging in endocrinology. Clinical Endocrinology 81 789-798. (doi:10.1111/ cen.12566)

Schillaci O, Massa R \& Scopinaro F 2000 111In-pentetreotide scintigraphy in the detection of insulinomas: importance of SPECT imaging. Journal of Nuclear Medicine 41 459-462. (doi.org/10.1080/02841860600833152)

Sempoux C, Guiot Y, Dahan K, Moulin P, Stevens M, Lambot V, de Lonlay P, Fournet JC, Junien C, Jaubert F, et al. 2003 The focal form of persistent hyperinsulinemic hypoglycemia of infancy: morphological and molecular studies show structural and functional differences with insulinoma. Diabetes 52 784-794. (doi:10.2337/ diabetes.52.3.784)

Service FJ, McMahon MM, O’Brien PC \& Ballard DJ 1991 Functioning insulinoma - incidence, recurrence, and long-term survival of patients: a 60-year study. Mayo Clinic Proceedings 66 711-719. (doi:10.1016/S0025-6196(12)62083-7)

Service GJ, Thompson GB, Service FJ, Andrews JC, Collazo-Clavell ML \& Lloyd RV 2005 Hyperinsulinemic hypoglycemia with nesidioblastosis after gastric-bypass surgery. New England Journal of Medicine $\mathbf{3 5 3}$ 249-254. (doi:10.1056/NEJMoa043690)

Solchia E, Capella C \& Kloppel G 1997 Tumors of the pancreas. In Atlas of Tumor Pathology, edn 3, pp 120-144. Washington, DC, USA: Armed Forces Institute of Pathology.

Sowa-Staszczak A, Pach D, Mikołajczak R, Mäcke H, Jabrocka-Hybel A, Stefańska A, Tomaszuk M, Janota B, Jilis-Januszewska, Malecki M, et al. 2013 Glucagonlike peptide-1 receptor imaging with [Lys40(Ahx-HYNIC-99mTc/EDDA)NH2]-exendin-4 for the detection 
of insulinoma. European Journal of Nuclear Medicine and Molecular Imaging 40 524-531. (doi:10.1007/s00259-012-2299-1)

Sowa-Staszczak A, Trofimiuk-Müldner M, Stefańska A, Tomaszuk M, Buziak-Bereza M, Gilis-Januszewska A, Jabrocka-Hybel A, Glowa B, Malecki M, Bednarczuk T, et al. 2016 99mTc labeled glucagon-like peptide-1-analogue (99mTc-GLP1) scintigraphy in the management of patients with occult insulinoma. PLOS ONE 11 e0160714. (doi:10.1371/journal.pone.0160714)

Strosberg J, El-Haddad G, Wolin E, Hendifar A, Yao J, Chasen B, Mittra E, Kunz PL, Kulke MH, Jacene H, et al. 2017 Phase 3 trial of 177Lu-dotatate for midgut neuroendocrine tumors. New England Journal of Medicine 376 125-135. (doi:10.1056/NEJMoa1607427)

Tessonnier L, Sebag F, Ghander C, DeMicco C, Reynaud R, Palazzo FF, Conte-Devolx B, Henry JF, Mundler O \& Taieb D 2010 Limited value of 18F-F-DOPA PET to localize pancreatic insulin-secreting tumors in adults with hyperinsulinemic hypoglycemia. Journal of Clinical Endocrinology and Metabolism 95 303-307. (doi:10.1210/jc.2009-1357)

Thompson SM, Vella A, Thompson GB, Rumilla KM, Service FJ, Grant CS \& Andrews JC 2015 Selective arterial calcium stimulation with hepatic venous sampling differentiates insulinoma from nesidioblastosis. Journal of Clinical Endocrinology and Metabolism 100 4189-4197. (doi:10.1210/jc.2015-2404)

Uchigata Y \& Hirata Y 1999 Insulin autoimmune syndrome (IAS, Hirata disease). Annals of Internal Medicine 150 245-253. (doi.org/10.1530/ endoabs.32.p289)

Van Meijeren J, Timmer I, Brandts H, Janssen I \& de Boer H 2017 Evaluation of carbohydrate restriction as primary treatment for postgastric bypass hypoglycemia. Surgery for Obesity and Related Diseases 13 404-410. (doi:10.1016/j.soard.2016.11.004)

van Schaik E, van Vliet EI, Feelders RA, Krenning EP, Khan S, Kamp K, Valkema R, van Nederveen FH, Teunissen JJ, Kwekkeboom DJ, et al. 2011 Improved control of severe hypoglycemia in patients with malignant insulinomas by peptide receptor radionuclide therapy. Journal of Clinical Endocrinology and Metabolism 96 3381-3389. (doi:10.1210/jc.2011-1563)
Vezzosi D, Bennet A, Rochaix P, Courbon F, Selves J, Pradere B, Buscail L, Susini C \& Caron P 2005 Octreotide in insulinoma patients: efficacy on hypoglycemia, relationships with octreoscan scintigraphy and immunostaining with anti-sst2A and anti-sst5 antibodies. European Journal of Endocrinology 152 757-767. (doi:10.1530/ eje.1.01901)

Warburg O 1956 On the origin of cancer cells. Science 123 309-314. (doi:10.1126/science.123.3191.309)

Whipple AO \& Frantz VK 1935 Adenoma of islet cells with hyperinsulinism: a review. Annals of Surgery 10112.

Wild D, Macke H, Christ E, Gloor B \& Reubi JC 2008 Glucagon-like peptide 1-receptor scans to localize occult insulinomas. New England Journal of Medicine 359 766-768. (doi:10.1056/ NEJMc0802045)

Wild D, Wicki A, Mansi R, Béhé M, Keil B, Bernhardt P, Christofori G, Ell PJ \& Mäcke HR 2010 Exendin-4-based radiopharmaceuticals for glucagonlike peptide-1 receptor PET/CT and SPECT/CT. Journal of Nuclear Medicine 51 1059-1067. (doi:10.2967/ jnumed.110.074914)

Wild D, Christ E, Caplin ME, Kurzawinski TR, Forrer F, Brändle M, Seufert J, Weber WA, Bomanji J, Perren A, et al. 2011 Glucagon-like peptide- 1 versus somatostatin receptor targeting reveals 2 distinct forms of malignant insulinomas. Journal of Nuclear Medicine $\mathbf{5 2}$ 1073-1078. (doi:10.2967/jnumed.110.085142)

Yao JC, Shah MH, Ito T, Lombard-Bohas C, Wolin EM, Van Cutsem E, Hobday TJ, Okusaka T, Capdevila J, de Vries EGE, et al. 2011 Everolimus for advanced pancreatic neuroendocrine tumors. New England Journal of Medicine 364 514-523. (doi:10.1056/ NEJMoa1009290)

Yates C, Neoh S, Konpa A, Fullinfaw R \& Colman P 2009 Factitious hypoglycaemia. Internal Medicine Journal 39 e15-e17. (doi:10.1111/j.1445-5994.2009.02100.x)

Zagury L, Moreira RO \& Guedes EP 2004 Insulinoma misdiagnosed as dumping syndrome after bariatric surgery. Obesity Surgery $\mathbf{1 4}$ 120-123. (doi:10.1381/096089204772787419)

Received in final form 4 April 2017

Accepted 7 April 2017

Accepted Preprint published online 11 April 2017
() 2017 Society for Endocrinology Printed in Great Britain
Published by Bioscientifica Ltd 